University of New Hampshire

University of New Hampshire Scholars' Repository

3-1994

\title{
The lifetime of excess atmospheric carbon dioxide
}

\author{
B Moore \\ University of New Hampshire - Main Campus, biii@cisunix.unh.edu \\ Rob Braswell \\ University of New Hampshire - Main Campus, rob.braswell@unh.edu
}

Follow this and additional works at: https://scholars.unh.edu/earthsci_facpub

\section{Recommended Citation}

Moore III, B., and B. H. Braswell (1994), The lifetime of excess atmospheric carbon dioxide, Global Biogeochem. Cycles, 8(1), 23-38, doi:10.1029/93GB03392.

This Article is brought to you for free and open access by the Earth Sciences at University of New Hampshire Scholars' Repository. It has been accepted for inclusion in Earth Sciences Scholarship by an authorized administrator of University of New Hampshire Scholars' Repository. For more information, please contact Scholarly.Communication@unh.edu. 


\title{
The lifetime of excess atmospheric carbon dioxide
}

\author{
Berrien Moore, III and B. H. Braswell \\ Institute for the Study of Earth, Oceans, and Space, University of New Hampshire, Durham
}

\begin{abstract}
We explore the effects of a changing terrestrial biosphere on the atmospheric residence time of $\mathrm{CO}_{2}$ using three simple ocean carbon cycle models and a model of global terrestrial carbon cycling. We find differences in model behavior associated with the assumption of an active terrestrial biosphere (forest regrowth) and significant differences if we assume a donordependent flux from the atmosphere to the terrestrial component (e.g., a hypothetical terrestrial fertilization flux). To avoid numerical difficulties associated with treating the atmospheric $\mathrm{CO}_{2}$ decay (relaxation) curve as being well approximated by a weighted sum of exponential functions, we define the single half-life as the time it takes for a model atmosphere to relax from its present-day value half way to its equilibrium $\mathrm{pCO}_{2}$ value. This scenario-based approach also avoids the use of unit pulse (Dirac Delta) functions which can prove troublesome or unrealistic in the context of a terrestrial fertilization assumption. We also discuss some of the numerical problems associated with a conventional lifetime calculation which is based on an exponential model. We connect our analysis of the residence time of $\mathrm{CO}_{2}$ and the concept of single half-life to the residence time calculations which are based on using weighted sums of exponentials. We note that the single half-life concept focuses upon the early decline of $\mathrm{CO}_{2}$ under a cutoff/decay scenario. If one assumes a terrestrial biosphere with a fertilization flux, then our best estimate is that the single half-life for excess $\mathrm{CO}_{2}$ lies within the range of 19 to 49 years, with a reasonable average being 31 years. If we assume only regrowth, then the average value for the single halflife for excess $\mathrm{CO}_{2}$ increases to 72 years, and if we remove the terrestrial component completely, then it increases further to 92 years.
\end{abstract}

\section{Introduction}

Since ancient times humans have modified natural systems, but only since the beginning of the industrial revolution has human activity significantly altered biogeochemical cycling at the planetary scale. The magnitude of human disturbance to the biogeochemical cycles may now be approaching a critical level; the values of important state variables, such as the concentration of atmospheric $\mathrm{CO}_{2}$, are moving into a range unprecedented during the past one million years. The pool of carbon in the atmosphere (in the form of $\mathrm{CO}_{2}$ ) increased from about 590 to almost $755 \mathrm{Pg} \mathrm{C}\left(1 \mathrm{Pg} \mathrm{C}=1 \times 10^{15} \mathrm{~g} \mathrm{C}=1\right.$ billion metric tons $\left.\mathrm{C}\right)$ during the 225 years between 1765 and 1991 as a result of fossil fuel burning and forest clearing. The annual rate of increase is currently about $2 \mathrm{ppm}(\mathrm{V})$ per year (equivalent to roughly $0.6 \%$ per year). We have a direct record of this increase since 1958 [Keeling, 1986] and a number of indirect records (from ice cores) of the increase over the past two centuries, which show that the concentration of $\mathrm{CO}_{2}$ has increased by more than $25 \%$ (e.g., Neftel et al., 1985; Raynaud and Barnola, 1985; Friedli et al., 1986; Siegenthaler and Oeschger, 1987] since the mid-1700s (Figure 1). Moreover, from the ice core records we know that the concentration of carbon dioxide was relatively constant from the beginning of the present interglacial period ( 10,000 B.P.) to the onset of increases in the 18th century [Siegenthaler, 1989].

The primary human activities contributing to this change are fossil fuel combustion and modifications of global vegetation through land use (e.g., biomass burning and conversion to agri-

Copyright 1994 by the American Geophysical Union.

Paper number $93 \mathrm{~GB} 03392$.

0886-6236/94/93GB-03392\$10.00. culture). For the period 1980-1989 an average of 5.4 Pg C per year as $\mathrm{CO}_{2}$ was released to the atmosphere from the burning of fossil fuels, and it is estimated that an average of $-0.6-2.6 \mathrm{Pg} \mathrm{C}$ per year was emitted due to deforestation and land-use change during the same interval [e.g., Houghton and Skole, 1990; Watson et al., 1990; Bolin and Fung, 1992; Skole and Tucker, 1993, and Houghton, 1993b). Figure 2 shows an estimate of these two fluxes of anthropogenic $\mathrm{CO}_{2}$ from the mid-18th century to the present.

The increase in the atmospheric $\mathrm{CO}_{2}$ concentrations (as well as other radiatively active trace gases) due to human activity has produced serious concern regarding the heat balance of the global atmosphere. Specifically, the increasing concentrations of these gases will lead to an intensification of Earth's natural greenhouse effect [Shine et al. 1990; Watson et al., 1990; Isaksen et al., 1992]. Shifting this balance will force the global climate system in ways which are not well understood, given the complex interactions and feedbacks involved, but there is a general consensus that global patterns of temperature and precipitation will change, though the magnitude, distribution and timing of these changes are far from certain. The results of general circulation models indicate that globally averaged surface temperatures could increase by as much as $1.5^{\circ}-4.5^{\circ} \mathrm{C}$ [e.g., Mitchell et al., 1990; Gates et al., 1992] in a world with an atmospheric concentration of $\mathrm{CO}_{2}$ twice that of the preindustrial period (i.e., a world where the concentration would be roughly $550-580 \mathrm{ppm}$ ).

The uncertainty of future climate change does not rest solely on issues of physical-climate system dynamics and their representation in general circulation models. Understanding the carbon cycle (Figure 3 ) is a key to comprehending the changing terrestrial biosphere and to developing a reasonable range of future concentrations of carbon dioxide and other greenhouse gases [e.g., Bacastow and Keeling, 1973; Bolin et al., 1979; 
ATMOSPHERIC CO2 DATA

FROM ICE CORES AND DIRECT MEASUREMENTS

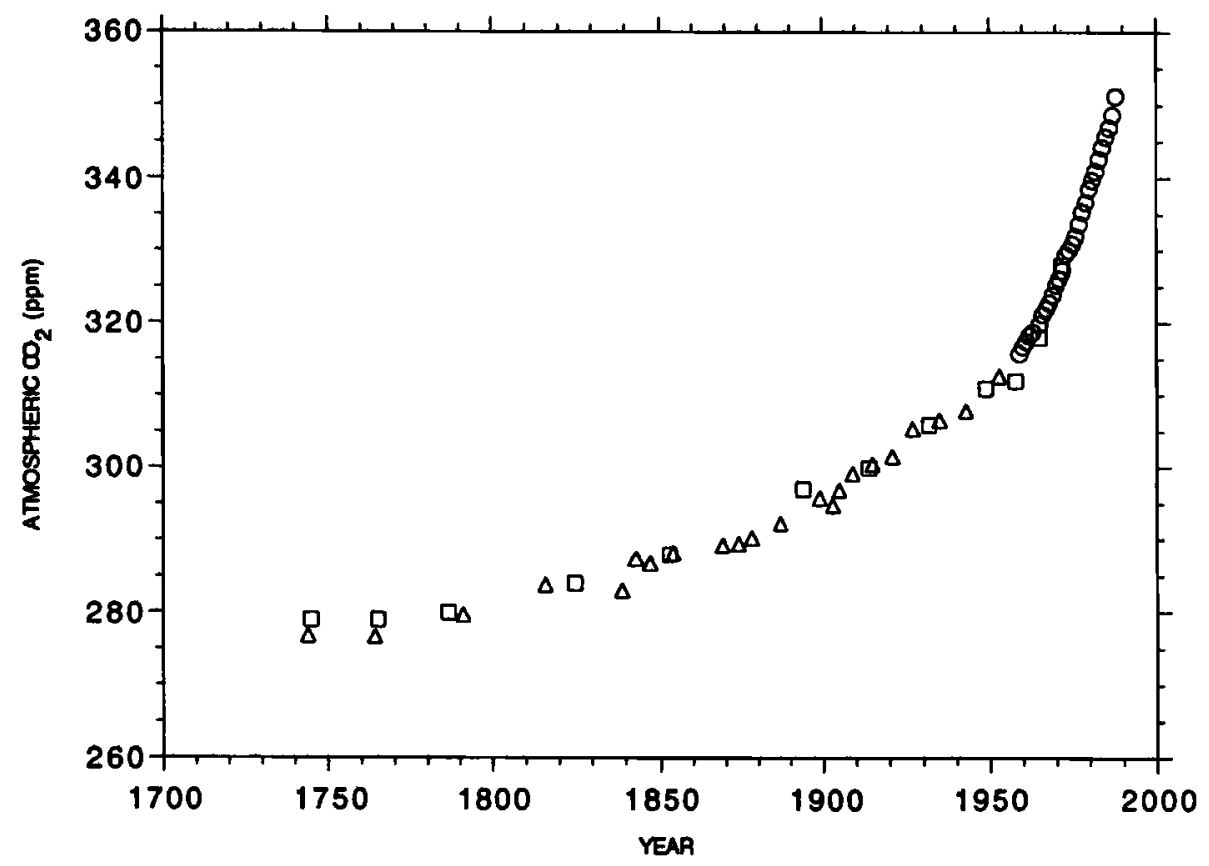

Figure 1. Historical atmospheric $\mathrm{CO}_{2}$ concentrations $\left(\mathrm{pCO}_{2}\right)$. The squares and triangles represent data derived from ice core measurements at Siple Station, Antarctica. The circles are the annual averaged atmospheric measurements from Mauna Loa Observatory (the Keeling record).

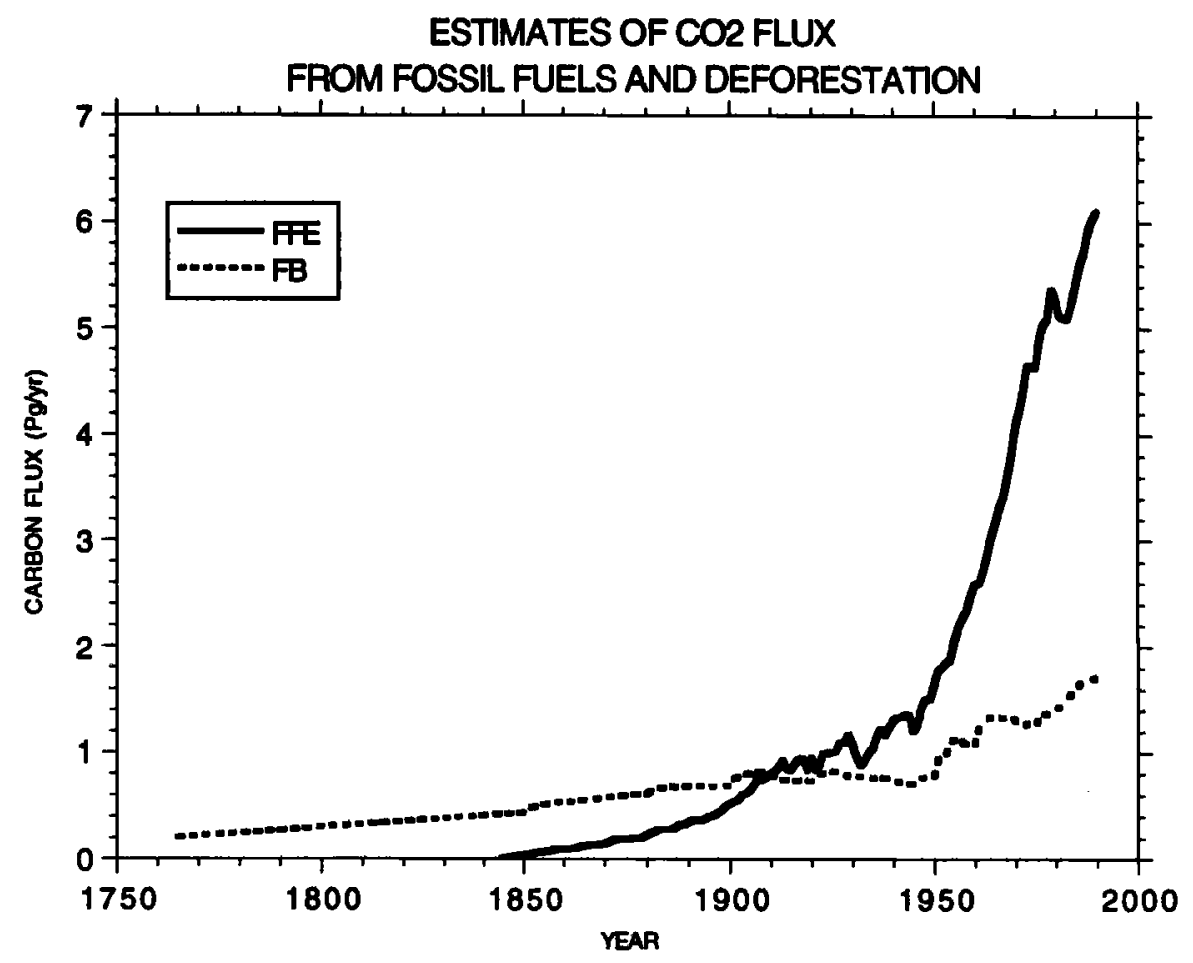

Figure 2. The fossil fuel emissions record $\left(\mathrm{F}_{\mathrm{FR}}\right)$ [Rotty and Marland, 1986; Marland, 1989; Andres et al., 1993] is accurate to within about $10 \%$, but the estimate of biotic flux due to land use change $\left(\mathrm{F}_{\mathrm{B}}\right)$ [Houghton, 1993b] is less certain, especially for the less recent numbers, because of a lack of a detailed historical accounting of global land use patterns. It can be seen from this figure that until about 1920 , deforestation contributed more to the atmospheric flux than fossil fuel burning, which did not become significant until the start of the current industrial period in the 1860 s. 


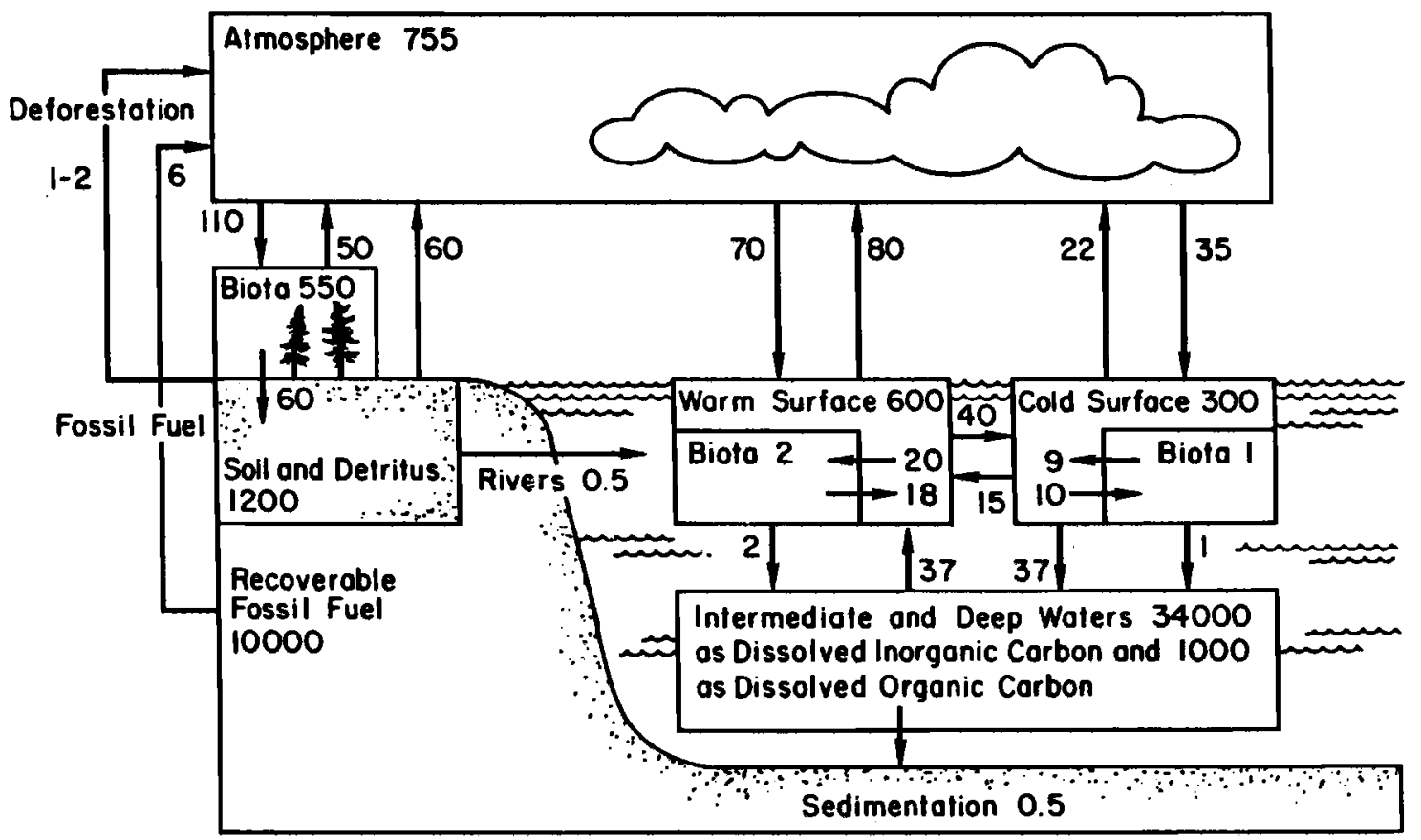

Figure 3. The global carbon cycle (adapted from Moore [1985]). The values within compartments are in units of $\mathrm{Pg} \mathrm{C}$, and the fluxes (arrows) are in units of $\mathrm{Pg} \mathrm{C} / \mathrm{yr}$.

Björkstrom, 1979; Bolin, 1981; Moore, 1985; Schlesinger, 1991; Bolin and Fung, 1992]. Conversely, our predictions about the physical-climate system and climate change are confounded by the fact that the carbon cycle is still not adequately understood or quantified globally. We remain uncertain about the role of the oceans in carbon dioxide exchange; they are without question a sink for anthropogenic $\mathrm{CO}_{2}$, but the strength of this sink is somewhat unclear [e.g., Keeling et al., 1989, Tans et al., 1990, Sarmiento, 1991; Siegenthaler and Sarmiento, 1993; Sarmiento, 1993].

Uncertainty also centers on the role of terrestrial ecosystems, in which at least two factors govern the level of carbon storage. First, and most obvious, is the anthropogenic alteration of the Earth's surface, such as through the conversion of forest to agriculture, which can result in a net release of $\mathrm{CO}_{2}$ to the atmosphere. Second, and more subtle, are the possible changes in net ecosystem production (and hence carbon storage) resulting from changes in atmospheric $\mathrm{CO}_{2}$, other global biogeochemical cycles, and/or the physical-climate system. Ultimately, to address adequately such changes will require a much clearer understanding of the nitrogen and phosphorus cycles, since they are the limiting nutrients in most terrestrial ecosystems, but our knowledge of the way these biogeochemical cycles relate to the carbon cycle compares poorly with our general understanding of the individual cycles themselves. In sum, these uncertainties are reflected in our uncertainty' about the atmospheric lifetime of $\mathrm{CO}_{2}$ [e.g., Watson et al., 1990; Watson et al., 1992].

The lifetime of a trace atmospheric constituent may be thought of as the amount of time required for some significant portion of an excess quantity of the gas to be removed chemically or to be redistributed to another part of the Earth system. The uncertainty in the distribution of sources and sinks for carbon dioxide (and for other greenhouse gases such as methane) makes a determination of atmospheric lifetime difficult and ambiguous. Unfortunately, the lifetime for $\mathrm{CO}_{2}$ (as well as for the other radiatively important gases) is important to know and particularly valuable in the policy context; it is necessary for the calculation of greenhouse warming potentials (GWP) [Lashof and Ahuja, 1990; Watson et al., 1990. See also Maier-Reimer and Hasselmann, 1987).

The GWPs provide an index of the relative climatic impacts (costs) of the various greenhouse gases. The index takes into account the instantaneous radiative forcing of a single molecule $a_{i}$ and the response $c(t)$ of the system (atmospheric concentration as a function of time) to an instantaneous injection of gas:

$$
\mathrm{GWP}_{i}=\frac{\int_{0}^{\infty} a_{i} \cdot c_{i}(t) d t}{\int_{0}^{\infty} a_{r} \cdot c_{r}(t) d t}
$$

where the subscript $r$ refers to the reference molecule. The curves $c_{i}(t)$ are generally computed using geochemical box-models. If the reference molecule is $\mathrm{CO}_{2}$, and the radiative forcing is taken to be equal to one (i.e. all $a_{i}$ s are relative to $\mathrm{CO}_{2}$ ), then the denominator becomes:

$$
T_{\text {res }}=\int_{0}^{\infty} c(t) d t
$$

In the simple or idealized context, where the concentration curve decays exponentially (i.e., $c(t)=a \cdot \exp (-t / \tau)$ ), then the integral (2) is $\tau$, which is simply the length of time required for $c(t)$ to decline from any value along its trajectory to $1 / \mathrm{e}$ of that value. Hence $\tau$ is often called the e-folding time. Generally, $c(t)$ is not strictly exponential, so the integral itself is called the residence time $\left(T_{\text {ress }}\right)$. On the basis of results of the convenient assumption of $c(t)=a \cdot \exp (-t / \tau)$, one often approximates the relaxation of the concentration by a weighted sum of exponentials (compare Section 6).

We will show that calculating integral (2) presents two types of difficulties. First, most model-derived estimates of the relaxation of the concentration of $\mathrm{CO}_{2}$ reveal a function which is not 
always well approximated by weighted sums of exponentials even though these are often used to calculate $T_{\text {res }}$. Second, the function $c(t)$ is quite sensitive to assumptions about the terrestrial biosphere and the relaxation experiment. We turn our attention to the second difficulty first.

\section{Simple Global Carbon Cycle Model}

From the most elementary viewpoint, and focusing solely upon $\mathrm{CO}_{2}$, the global carbon cycle can be treated as a one box atmosphere linked to a submodel of terrestrial carbon dynamics and to an ocean carbon submodel. This is precisely the representation we employ in our experiments.

\subsection{The Ocean Carbon Submodels}

The net exchange of carbon between the atmosphere and the oceans is determined to a great extent by the carbonate chemistry of the upper mixed layer, the convective transport of dissolved carbon in the water, the diffusion of carbon dioxide across the air-sea boundary, and the sinking of detrital carbon originating from the biological production of marine organisms [Bolin, 1981; Broecker and Peng, 1982; Moore, 1985; Sarmiento, 1991). All of these processes govern the exchange of carbon dioxide between the sea surface and the atmosphere, and all have been represented in models to varying extents; however, all do not play an essential or the same role in the perturbation problem posed by the increase in carbon dioxide (Broecker, 1991; Sarmiento, 1991).

We investigate the effect of using different (simple) representations of ocean carbon dynamics on the atmospheric concentration of $\mathrm{CO}_{2}$ using three atmosphere-ocean box models, either standing alone or in a global carbon model which includes a terrestrial component. (For a discussion of more complex models see Maier-Reimer and Hasselmann [1987], Keeling et al. [1989], and Maier-Reimer [1993].) The submodels are as follows:

1. The box-diffusion model (BD, Figure 4) represents the turnover of carbon below 75 meters by a diffusion equation in

\section{Box-diffusion Model (Oeschgen and colleagues)}

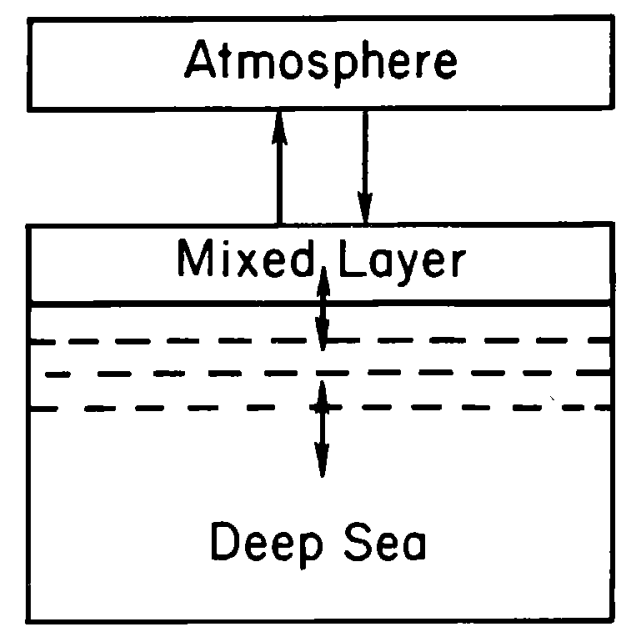

Figure 4. Box-diffusion model. The turnover of carbon below 75 $\mathrm{m}$ is represented by a diffusion equation. A constant coefficient of diffusivity is estimated to match an idealized profile of ${ }^{14} \mathrm{C}$ [Oeschger et al., 1975].

\section{Box-diffusion Model with Polar Outcrops (Siegenthaler and colleagues)}

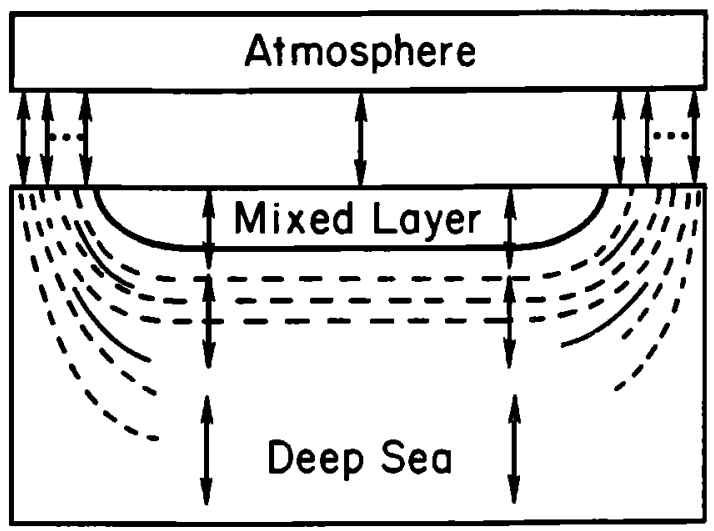

Figure 5. Outcrop-diffusion model. Direct ventilation of the intermediate and deep oceans at high latitudes is allowed by incorporating outcrops for all sublayers into the box-diffusion formulation [Siegenthaler, 1983].

which a constant coefficient of diffusivity has been stimated to match an idealized profile of natural carbon-14 or bomb carbon14 [Oeschger et al., 1975].

2. The outcrop-diffusion model (OC, Figure 5) allows direct ventilation of the intermediate and deep oceans at high latitudes by incorporating outcrops for all sublayers into the box-diffusion formulation [Siegenthaler, 1983]. It is essentially the box-diffusion model with the addition of direct connections between the atmosphere and the deeper ocean layers. In a similar manner a constant coefficient of diffusivity is estimated to match an idealized profile of natural carbon-14 or bomb carbon-14.

3. For the 12-box model (12B, Figure 6) the Atlantic and Pacific-Indian Oceans are each divided into surface, intermediate, deep, and bottom water compartments. The Arctic and Antarctic Oceans are divided into surf́ace and deepwater compartments. The model is calibrated against multiple tracer distributions [Bolin et. al., 1983].

The three models have much in common: They are all diagnostic rather than prognostic; each uses carbon-14 in the parameterization process (in fact, carbon-14 is the basic clock for all of the models and hence controls much of their response); each includes ocean carbon chemistry (buffer or Revelle factor); and they all include some form of ocean mixing. There are, however, some major differences. Ocean biology is explicitly included in only one (12B); whereas it is simply incorporated into the parameterization of the diffusive process in both the BD and $O C$ models. As far as transport is concerned, in the box-diffusion and outcrop-diffusion models all of the physics is captured by a single constant eddy diffusivity term; the Bolin model (12B) has both advection and eddy diffusivities. Deep water formation (the sinking of cold, $\mathrm{CO}_{2}$-rich water at high latitudes) is not explicitly considered in the box-diffusion model. The treatment of ocean chemistry also varies in complexity: the 12B model includes a detailed handling of the carbonate-borate equilibrium system; the BD model uses a constant buffer factor; and the OC model employs a quadratic that is a fit to measured data. Perhaps most importantly, the geometrical configurations are quite different, as can be seen in Figures 4-6. In addition, there are a host of smaller 


\section{Box Model of Bolin et al. (1983)}

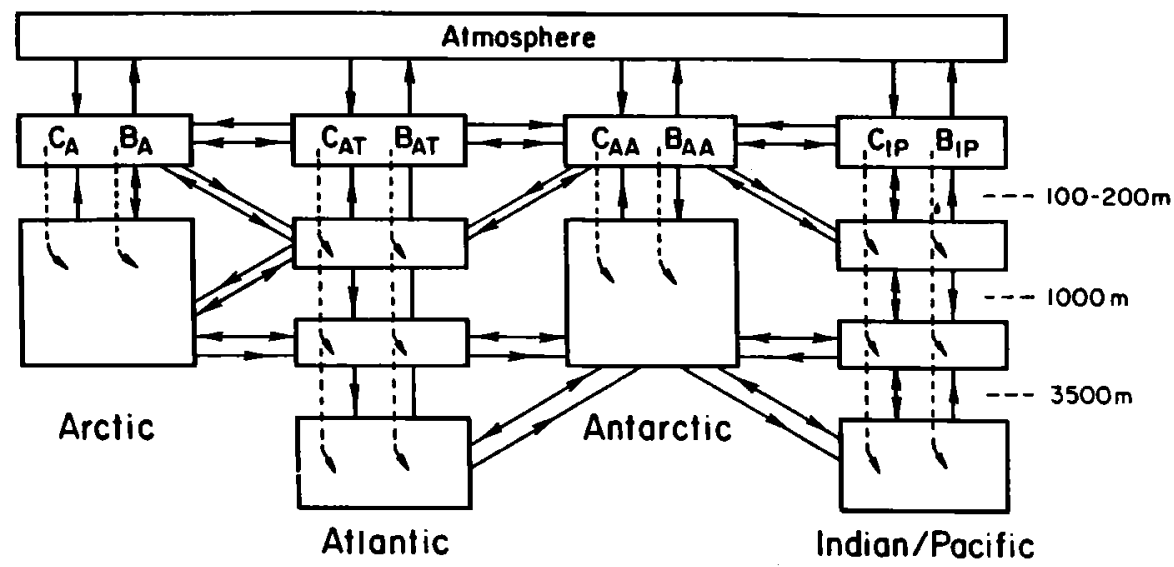

Figure 6. Twelve-box model. The Atlantic and Pacific-Indian oceans are each divided into surface, intermediate, deep, and bottom water components. The Arctic and Antarctic oceans are divided into surface and deep water components. The soft tissue and carbonate formation in surface boxes is indicated by $B$ and $C$, with appropriate subscripts for region, and the fluxes to and decomposition in deeper layers are indicated by the vertical dashed line and the branching solid arrow, respectively. The model is calibrated against multiple tracer distributions [Bolin et al., 1983].

differences, including the specification of ocean volume and surface area, parameterization procedures, and carbon-14 profiles.

As a result of these differences, we find a range of responses to the two simplest experiments that can be performed with these three atmosphere-ocean submodels: a calculation of the perturbation response to a forcing by fossil fuel $\mathrm{CO}_{2}$ alone ( $F_{F E}$, Figure 7) and to the forcing by $\mathrm{CO}_{2}$ from land use change as well as the fossil fuel-derived flux $\left(F_{B}+F_{F E}\right.$, Figure 8). A principal reason why all the models are so similar is the overarching importance of ${ }^{14} \mathrm{C}$ in setting the basic rates within the models [Moore, 1992].
(An interesting discussion of the ${ }^{13} \mathrm{C}$ constraints on ocean uptake of $\mathrm{CO}_{2}$ is provided by Broecker and Peng [1993].) The OC model is the most efficient in taking up $\mathrm{CO}_{2}$, and this is the result of the instantaneous flux of $\mathrm{CO}_{2}$ to deep layers. In general, however, all of the ocean-atmosphere models undershoot the data when forced by $F_{F E}$ alone and overshoot the record when both $F_{F E}$ and $F_{B}$ are used. Since there is evidence, based on historic reconstructions [Houghton et al., 1983; Houghton and Skole, 1990; Houghton et al., 1991; Houghton, 1991; Houghton, 1993b; Skole and Tucker, 1993] of an anthropogenically induced flux from the

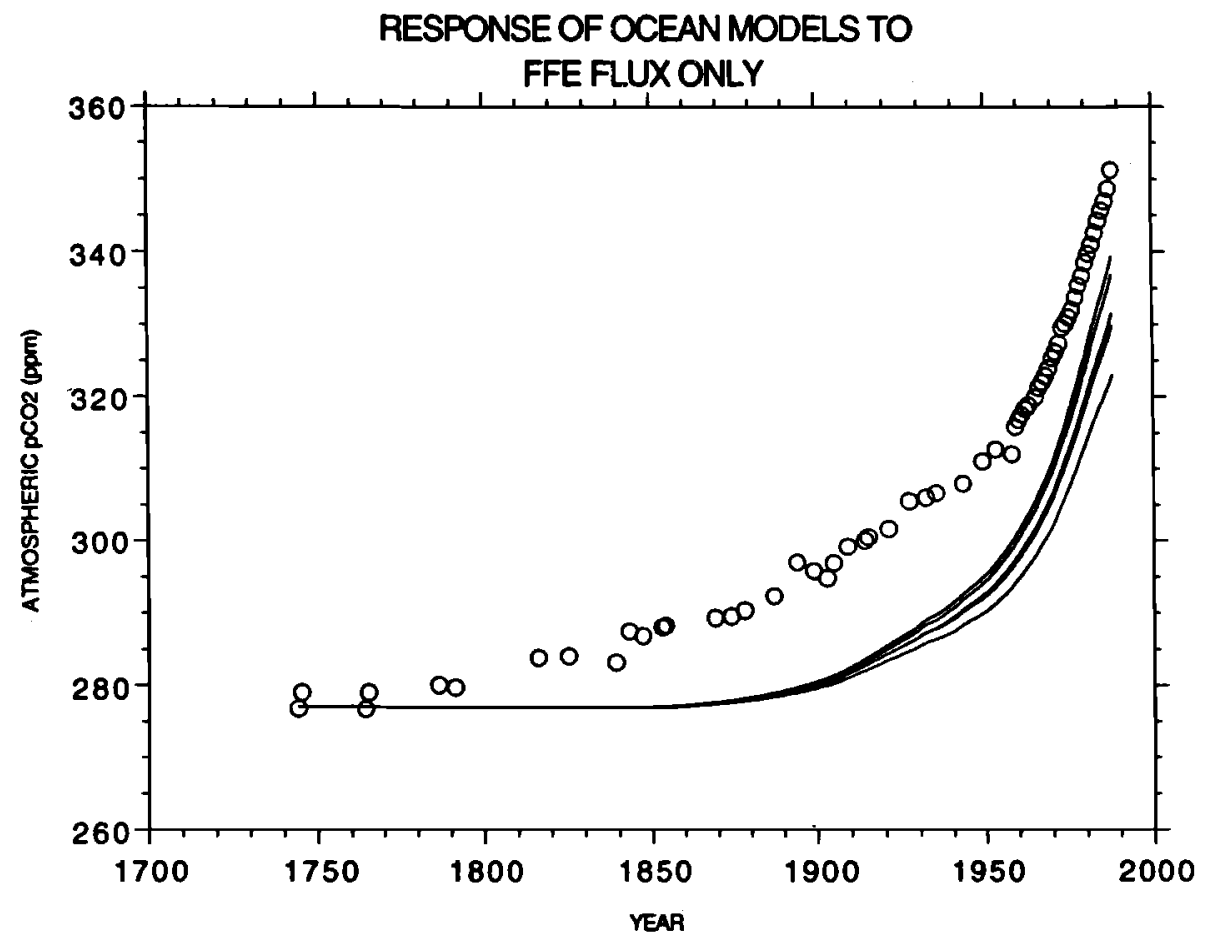

Figure 7. The responses of the ocean-atmosphere models to the historic fossil fuel forcing. All models were initialized at the 1744 ice core value for $\mathrm{pCO}_{2}$. Circles represent the atmospheric $\mathrm{CO}_{2}$ record (compare Figure 1). 
biosphere to the atmosphere, the discrepancy between model and data in Figure 8 has given rise to the notion of a "missing carbon sink." This is part of the motivation for considering the terrestrial component.

\subsection{The Terrestrial Carbon Submodel}

The net exchange of carbon between terrestrial vegetation and the atmosphere may be considered to be the sum of three fluxes: gross photosynthesis, autotrophic plant respiration, and heterotrophic (soil microbial) respiration [e.g., Aber and Melillo, 1991]. (This latter respiration can cover also the anthropogenic perturbation of biomass burning though the human role is not usually considered in these biological terms.) The gross fluxes between the terrestrial system and the atmosphere are similar to those for the oceans (100 Pg C per year, Figure 3; see also Bolin et al. [1979] and Bolin [1981]), but the considerably smaller terrestrial pool size leads to a much faster turnover time than for the oceans [Björkstrom, 1979].

Motivated, in part, by the issue of a missing carbon sink and partly by physiology, it has been suggested [e.g., Bacastow and Keeling, 1973] that terrestrial vegetation may be "fertilized" by the increasing concentration of $\mathrm{CO}_{2}$. Though the issue is controversial (Strain and Cure [1985], Bazzaz [1990], Garbutt et al. [1990], Bazzaz and Fajer [1992], Dlaz et al. [1993], see also Dai and Fung [1993] for a climate-based hypothesis and Houghton [1993a] for a land use-based hypothesis), it is possible that terrestrial ecosystems are responding to the rapid increase in atmospheric $\mathrm{CO}_{2}$ concentration by producing more biomass and/or storing more soil carbon, thereby balancing the global carbon budget. For instance, the increasing concentration of $\mathrm{CO}_{2}$ in the atmosphere may raise $\mathrm{C} / \mathrm{N}$ ratios by either making plants more water efficient (more carbon fixed per $\mathrm{H}_{2} \mathrm{O}$ transpired) or through other indirect biochemical mechanisms (e.g., enhancing carbohy- drate formation, which is generally not balanced by increased nitrogen uptake). Consequently, there is the possibility that higher $\mathrm{CO}_{2}$ levels may lead to an increase in net primary production and perbaps net ecosystem production (carbon storage).

The possible existence of a fertilization effect, the rapid response of the land biota-soil system, and the fact that one of the major fluxes to the atmosphere $\left(F_{B}\right)$ is actually due to alteration of the terrestrial biosphere make it appropriate to include terrestrial dynamics in our attempt to address the issue of the lifetime of excess atmospheric $\mathrm{CO}_{2}$. Emanuel et al. [1984] has developed a highly aggregated model of global carbon cycling which is similar in scope to the three simple ocean models presented in the previous section. This model (Figure 9) is composed of a set of eight coupled differential equations (Table 1 contains the terrestrial components) which govern the flow of carbon between reservoirs representing the atmosphere, the surface ocean, the deep ocean, nonwoody parts of trees, woody parts of trees, ground vegetation, detritus/decomposers, and soils. Its modular structure means that one can replace relatively easily Emanuel's two-box ocean (Figure 9) with the other simple ocean models that we are considering. In the current context Emanuel's model is of interest, in part, because it is a convenient way to handle terrestrial carbon fluxes associated with forest clearing and reestablishment. The model deals with these activities in the following way: (1) A specified mass of carbon is released (due to land-use change) from 'woody' and 'nonwoody' parts of trees as a function of time, in a ratio determined by their relative sizes. (2) A fraction of the carbon released is transferred immediately to the atmosphere, and a fraction enters the detritus/decomposers pool. The remainder is assumed to be in a very slow turnover pool (e.g., timber products). (3) All vegetation pools experience a logistic growth recovery with a prescribed rate and with a dynamically varying asymptote. (4) Upon clearing, the asymptotic level for trees decreases, and the asymptotic level for ground vegetation increases.

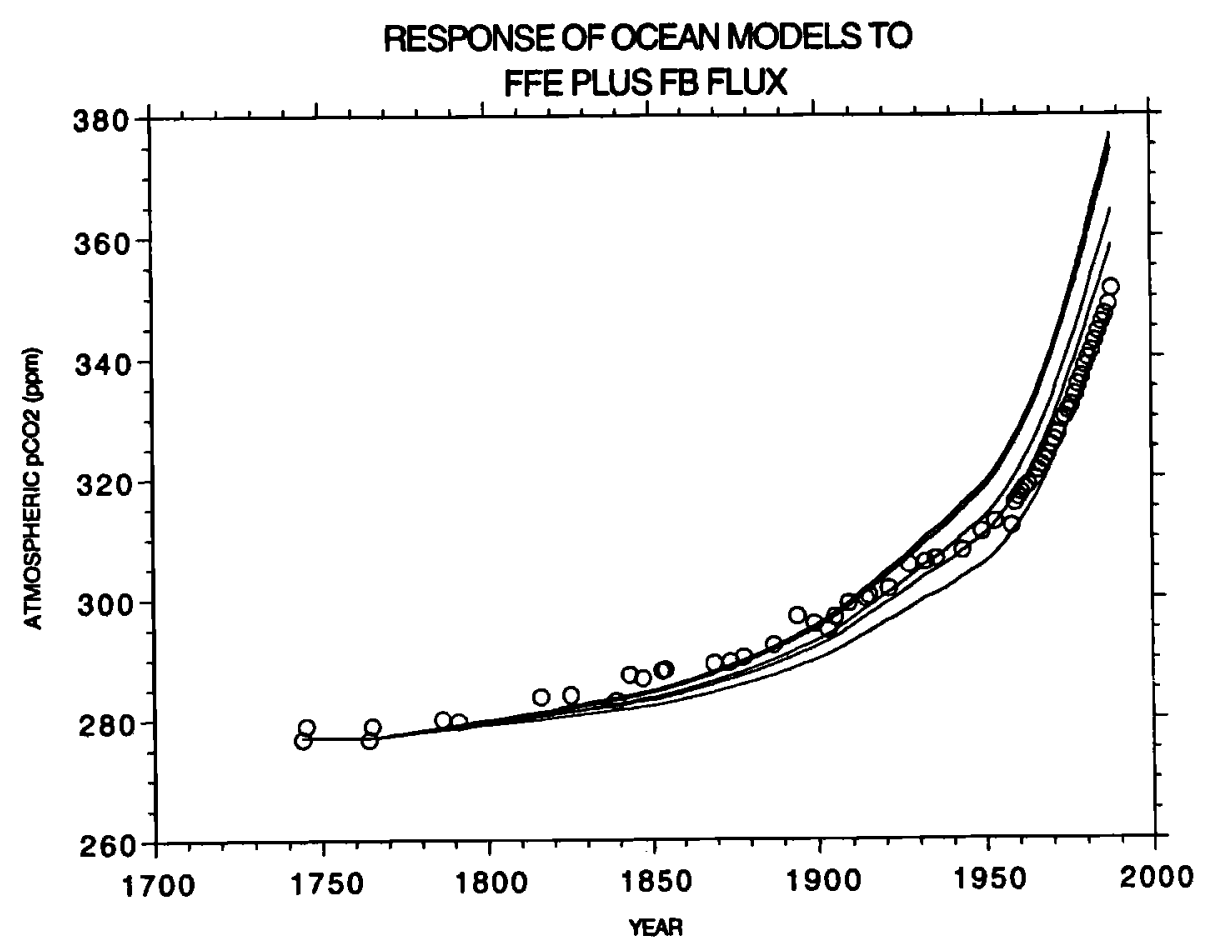

Figure 8. The responses of the ocean-atmosphere models to the historic fossil fuel forcing plus an estimate of biotic (deforestation) flux. All models were initialized at the 1744 ice core value for $\mathrm{pCO}_{2}$. Circles represent the atmospheric $\mathrm{CO}_{2}$ record (compare Figure 1). 


\section{GLOBAL CARBON CYCLE MODEL OF EMANUEL, ET AL. (1984)}

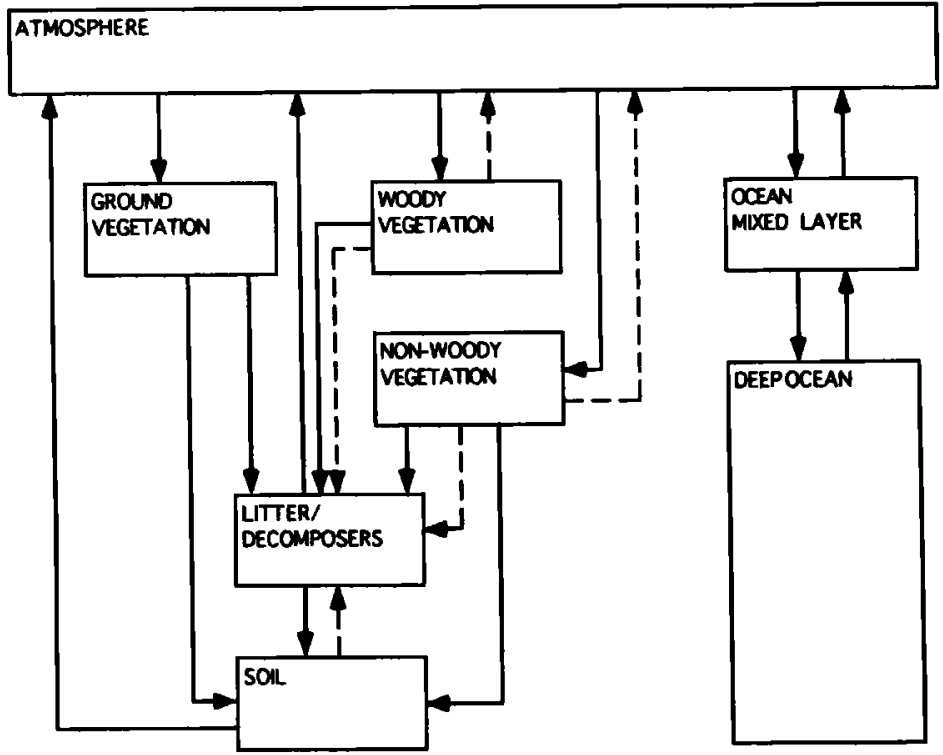

Figure 9. Globally averaged carbon cycle model [Emanuel et al., 1984]. The atmosphere exchanges carbon with terrestrial components, and with the oceans. Solid arrows represent equilibrium (natural) carbon fluxes. Dashed arrows représent fluxes associated with forest clearing activities.

We remark that given a clearing and abandonment time series, the interplay of these dynamics determines the flux $F_{B}$. We also note that the structure of the model allows an easy modification to be made to include a fertilization effect, which we later discuss in detail.
Returning to the global carbon cycle, our basic approach is to modify Emanuel's global carbon cycle model in two ways. First, we replace his two-box ocean model with (in turn) the box-diffusion model, the outcrop-diffusion model, and the 12-box ocean model; and second, we develop a simple treatment of the terres-

Table 1. Differential Equations Governing the Carbon Dynamics in the Emanuel et al. [1984] Model

\begin{tabular}{|c|c|}
\hline Compartment & Equation \\
\hline $\begin{array}{l}\text { Atmosphere } \\
\text { Trees (Nonwoody Fraction) } \\
\text { Trees (Woody Fraction) } \\
\text { Ground Vegetation } \\
\text { Detritus/Decomposers } \\
\text { Soil Carbon }\end{array}$ & $\begin{array}{l}d C_{\gamma} / d t=F_{F E}+\phi_{A} F_{B}+F_{O A}+\alpha_{51} C_{5}+\alpha_{61} C_{6}-\left(F_{12}+F_{13}+F_{14}\right) \\
d C_{2} / d t=F_{12}-\alpha_{25} C_{2}-F_{B} C_{2} /\left(C_{2}+C_{3}\right) \\
d C_{5} / d t=F_{13}-\left(\alpha_{35}+\alpha_{36}\right) C_{3}-F_{B} C_{3} /\left(C_{2}+C_{3}\right) \\
d C_{d} / d t=F_{14}-\left(\alpha_{45}+\alpha_{46} C_{4}\right. \\
d C_{5} d d t=\alpha_{25} C_{2}+\alpha_{35} C_{3}+\alpha_{45} C_{4}-\left(\alpha_{56}+\alpha_{51}\right) C_{5}+\phi_{D} F_{B}+\psi F_{B} \\
d C_{\delta} d d t=\alpha_{36} C_{3}+\alpha_{46} C_{4}+\alpha_{56} C_{5}-\alpha_{61} C_{6}-\psi F_{B}\end{array}$ \\
\hline \multicolumn{2}{|l|}{ Assimilation Fluxes } \\
\hline $\begin{array}{l}\text { Atmosphere to Trees (Nonwoody Fraction) } \\
\text { Atmosphere to Trees (Woody Fraction) } \\
\text { Atmosphere to Ground Vegetation }\end{array}$ & $\begin{array}{l}F_{12}=v_{T} C_{2}-\rho_{1} C_{2}{ }^{2} \\
F_{13}=\left(F_{J 3} 0 / F_{12} 0\right) F_{12} \\
F_{14}=v_{T} C_{4}-\rho C_{4}\end{array}$ \\
\hline Variable & Definition \\
\hline $\begin{array}{l}C_{i} \\
F_{i j} \\
\alpha_{i j} \\
F_{F E} \\
F_{B} \\
F_{O A} \\
\phi_{A} \\
\phi_{D} \\
\psi F_{B} \\
F_{i j}^{0} \\
v_{T}^{\prime} \rho_{T} \\
v_{V} / \rho_{V}\end{array}$ & $\begin{array}{l}\text { mass of carbon } \\
\text { flux from } i \text { to } j \\
\text { transfer coefficient from } i \text { to } j \\
\text { fossil } \mathrm{CO}_{2} \text { flux } \\
\text { forest clearing } \mathrm{CO}_{2} \text { flux } \\
\text { net ocean - atmosphere flux } \\
\text { fraction of } F_{B} \text { diverted to atmosphere } \\
\text { fraction of } F_{B} \text { diverted to detritus / decomposers } \\
\text { soil to detritus flux associated with } F_{B} \\
\text { initial steady - state flux from } i \text { to } j \\
\text { post - disturbance equilibrium for } C_{2} \\
\text { post - disturbance equilibrium for } C_{3}\end{array}$ \\
\hline
\end{tabular}


trial fertilization term. By comparing the resulting hybrid models (E-BD, E-OC, and E-12B; both with and without fertilization) with results of the ocean-atmosphere models ( $B D, O C$, and 12B), we effectively perform the experiments on the residence time of $\mathrm{CO}_{2}$ in the atmosphere with the terrestrial biosphere switched on and off. We are thus able to investigate the effects of a fertilization assumption plus forest regrowth or just forest regrowth on the residence time of $\mathrm{CO}_{2}$ in the atmosphere. The modeled forest regrowth develops from a deforestation pattern for the period 1700 to the present and is constrained to produce the net flux in Figure 2.

\section{Characterization Of The Biotic Response}

As discussed in section 2.1, if the ocean-atmosphere models are forced with $F_{F E}$ and $F_{B}$ as input and the results compared to the record of atmospheric $\mathrm{pCO}_{2}$, there is a discrepancy (i.e., an overshoot; see Figure 8). This residual $\boldsymbol{R}$ (the difference between the model output, $\mathrm{pCO}_{2}{ }^{\mathrm{M}}$, and the $\mathrm{pCO}_{2}$ data) can be decomposed as:

$$
R=\left(\mathrm{pCO}_{2}-\mathrm{pCO}_{2}^{\mathrm{M}}\right)=R_{B}+R_{E 1}+R_{E 2}+R_{E 3}
$$

where $R_{B}$ is caused by some unspecified, hypothetical biological mechanism (e.g., the 'fertilization factor'), $R_{E I}$ results from inaccuracies in the models, $R_{E 2}$ results from uncertainty in the $\mathrm{pCO}_{2}$ data, and $R_{E 3}$ is due to uncertainty in the $F_{F E}$ and $F_{B}$ data. We will not attempt to characterize the latter three, so let $R_{E}=R_{E I}+R_{E 2}+$ $R_{E 3}$. The expression then becomes:

$$
R=R_{B}+R_{E}
$$

Thus the residual has been reduced to two terms: error associated with some ignored physiological or ecological process and error associated with uncertainties in information (data or model). Further, we will make the following two assumptions: $R_{E}<R_{B}$, and the residual $R_{B}$ may be associated with an increment $F_{r}$ in the net flux of carbon from the atmosphere to the terrestrial biota:

$$
\mathrm{F}_{\mathrm{s}}=p_{\mathrm{r}} \cdot \mathrm{F}_{\mathrm{mpp}}
$$

where (compare Table 1)

$$
F_{\text {npp }}=F_{12}+F_{13}+F_{14}
$$

To parameterize the fertilization factor $\rho_{r}$ there are several functional forms suggested in the literature. We have selected three different empirical relationships (logarithmic, logistic, and linear) to describe the fertilization enhancement as a function of elevated $\mathrm{CO}_{2}$

$$
\begin{aligned}
& \rho_{r}=a \cdot \log \left(\mathrm{C} / \mathrm{C}_{\mathrm{i}}\right) \\
& \rho_{r}=a \cdot \tanh \left(b\left(\mathrm{C} / \mathrm{C}_{\mathrm{i}}+c\right)\right) \\
& \rho_{r}=a \cdot\left(\mathrm{C} / \mathrm{C}_{\mathrm{i}}\right)+b
\end{aligned}
$$

where $\mathrm{C} / \mathrm{C}_{1}$ is the ratio of present to initial $\mathrm{pCO}_{2}$, and $a, b$, and $c$ are free parameters. Note that this treatment will not only vary the functional dependence, but also the number of free parameters. To obtain the values for those parameters, we must compute $F_{r}$ and $F_{n p p}$ from the carbon models (E-12B, E-OC, and E-BD) and perform a least-squares fit of $\rho_{r}$ to $F_{r} / F_{n p p}$ (see (5)).
In order to compute the missing flux $F_{r}$ we specify that the rate of change of the atmospheric $\mathrm{pCO}_{2}$ that is produced by the models is equivalent to the measured rate of change (i.e., $R=0$ ) and is given by

$$
\frac{d \mathrm{C}}{d t}=\frac{d \mathrm{C}_{1}}{d t}+F_{r}
$$

where $d \mathrm{C}_{1} / d t$ is the net flux to the atmosphere calculated by the models, and $d \mathrm{C} / d t$ may be obtained from the $\mathrm{pCO}_{2}$ record. Thus the residual flux, for each time step, may be calculated by a deconvolution procedure

$$
\begin{gathered}
F_{r}(t)=\frac{d \mathrm{C}}{d t}-\frac{d \mathrm{C}_{1}}{d t}= \\
\frac{d \mathrm{C}}{d t}-F_{F E}+\phi_{A} F_{B}+F_{O A}+\alpha_{51} \mathrm{C}_{5}+\alpha_{61} \mathrm{C}_{6}-\left(F_{12}+F_{13}+F_{14}\right)(11)
\end{gathered}
$$

where we have substituted the terms from Table 1 on the righthand side. The concept is simple: we add the flux $F_{r}$ to the righthand side of the derivative in (10) as the model proceeds. This is similar to the way in which deconvolution has been used to determine the biotic flux $\mathrm{F}_{\mathrm{B}}$ [e.g., Siegenthaler and Oeschger, 1987], given the fossil flux $\mathrm{F}_{\mathrm{FE}}$. Figure 10 shows the deconvolved missing flux $F_{r}$ for the ocean-atmosphere models and Figure 11 shows the graph of $F_{r} / F_{n p p}$ versus $C / C_{i}$ with the fitted curve for the logistic parameterization of $\rho_{r}$ using the E-12B model. We now have the following tools needed for our investigation: three ocean-atmosphere models, the corresponding ocean-terrestrialatmosphere models, an estimate of the evolution of the terrestrial component as a result of land use, and a set of parameterizations for dealing with a hypothetical biotic response to increasing $\mathrm{pCO}_{2}$.

\section{Single Half-Life}

Before investigating the response of these simple coupled carbon cycle models, we clarify our concerns about calculating atmospheric residence time of $\mathrm{CO}_{2}$ and suggest a simple interim index for model comparisons. The e-folding time is really just a mathematical way of saying when a decaying exponential curve will fall to $1 / \mathrm{e}$ of its original value. The conventional determination of lifetime ( $T_{\text {res; }}$ compare sections 1 and 6 ) is conceptually not much more substantive, and its calculation may present a number of difficulties which reduce its utility. Thus we introduce a simple indicator of atmospheric residence time, the single halflife $\left(T_{1 / 2}\right)$, which is the time required for the model atmosphere to relax from its present value (or some future value, though this would alter $T_{1 / 2}$ ) to half way to its new equilibrium value. This, of course, implies that we will not deal with the pulse response of the models, but with a more scenario-based approach which allows the models to respond to the historical inputs (e.g., $F_{\mathrm{FE}}$ and $\mathrm{F}_{B}$; see Figure 2) followed by cutting the forcing to zero. From any cutoff time (in the past, present, or future) onward, one simply records the decay of the concentration $c(t)$ of atmospheric $\mathrm{CO}_{2}$ towards its new equilibrium. We acknowledge that this concept or index focuses attention upon the initial response and ignores the mid-term to very long term aspects of $c(t)$.

There are only two assumptions involved in these computations which are necessary to compare results across models: first, the models are all required to reproduce the historic $\mathrm{pCO}_{2}$ record, and second, though not really essential, the equilibrium value is 


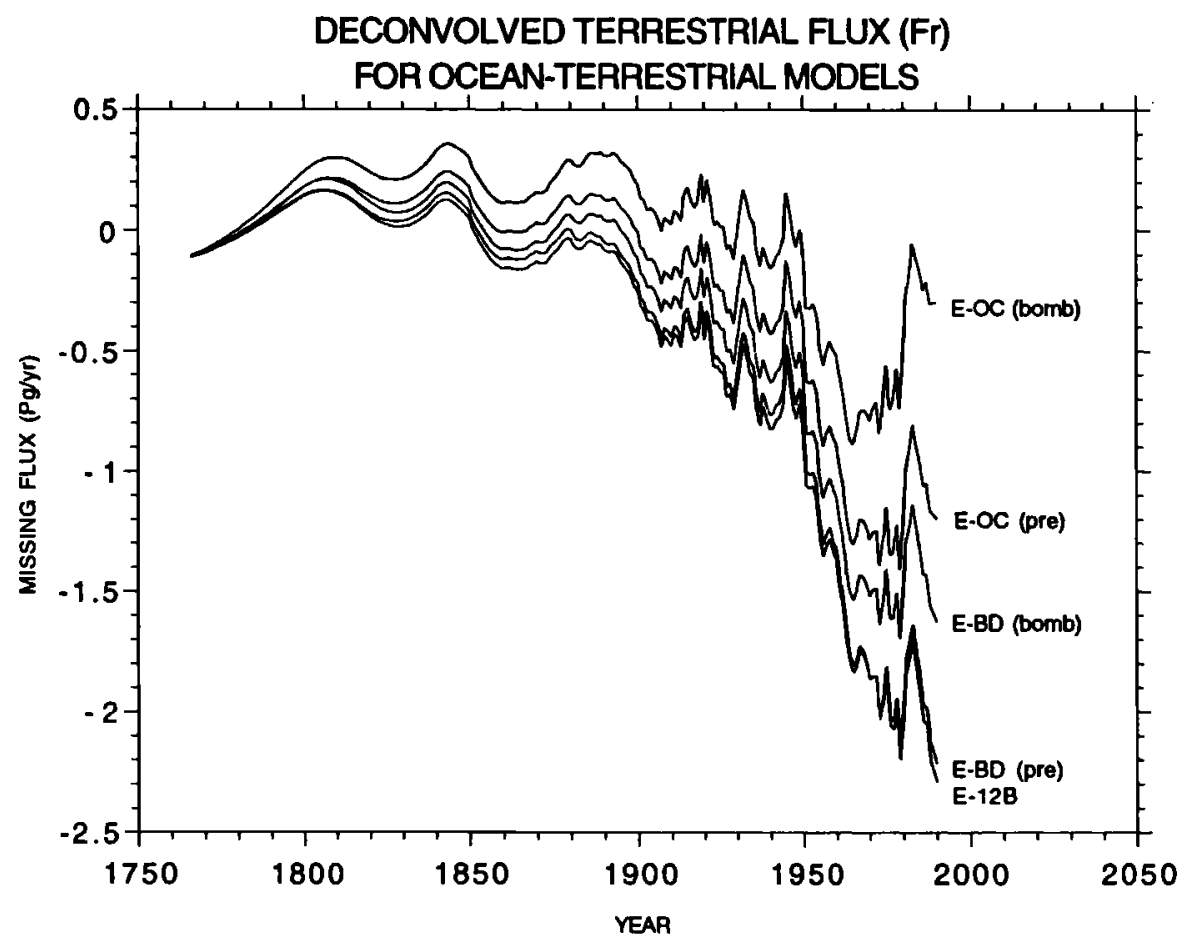

Figure 10. Deconvolved flux $\left(F_{r}\right)$ determined by the ocean-terrestrial-atmosphere models. This flux (generally a sink for later years) represents the additional input required for the models to reproduce the $\mathrm{pCO}_{2}$ record; it may be associated with the hypothetical response of the terrestrial biosphere to increasing ambient $\mathrm{CO}_{2}$ concentrations.

approximately the same for all models. This assumed equilibrium $\mathrm{pCO}_{2}$ is a theoretical value based on the partitioning between atmosphere and ocean. Because of the carbonate buffer system the relationship between a percentage increase in atmospheric carbon dioxide $\left(\Delta \mathrm{C}_{\mathrm{a}} / \mathrm{C}_{\mathrm{a}}\right)$ and a percentage increase in oceanic dissolved inorganic carbon $\left(\Delta \mathrm{C}_{\mathrm{o}} / \mathrm{C}_{\mathrm{o}}\right)$ may be approximated by

$$
\Delta \mathrm{C}_{\mathrm{a}} / \mathrm{C}_{\mathrm{a}}=10 \cdot\left(\Delta \mathrm{C}_{\mathrm{o}} / \mathrm{C}_{\mathrm{o}}\right)
$$

This factor of ten is called the Revelle factor. If we note that the cumulative release of $\mathrm{CO}_{2}$ from $\mathrm{F}_{\mathrm{FE}}$ and $\mathrm{F}_{\mathrm{B}}$ combined is equal to $377 \mathrm{Pg}$, and assume that the initial values for the total oceanic dissolved inorganic carbon and atmospheric $\mathrm{C}$ are $38200 \mathrm{Pg}$ and

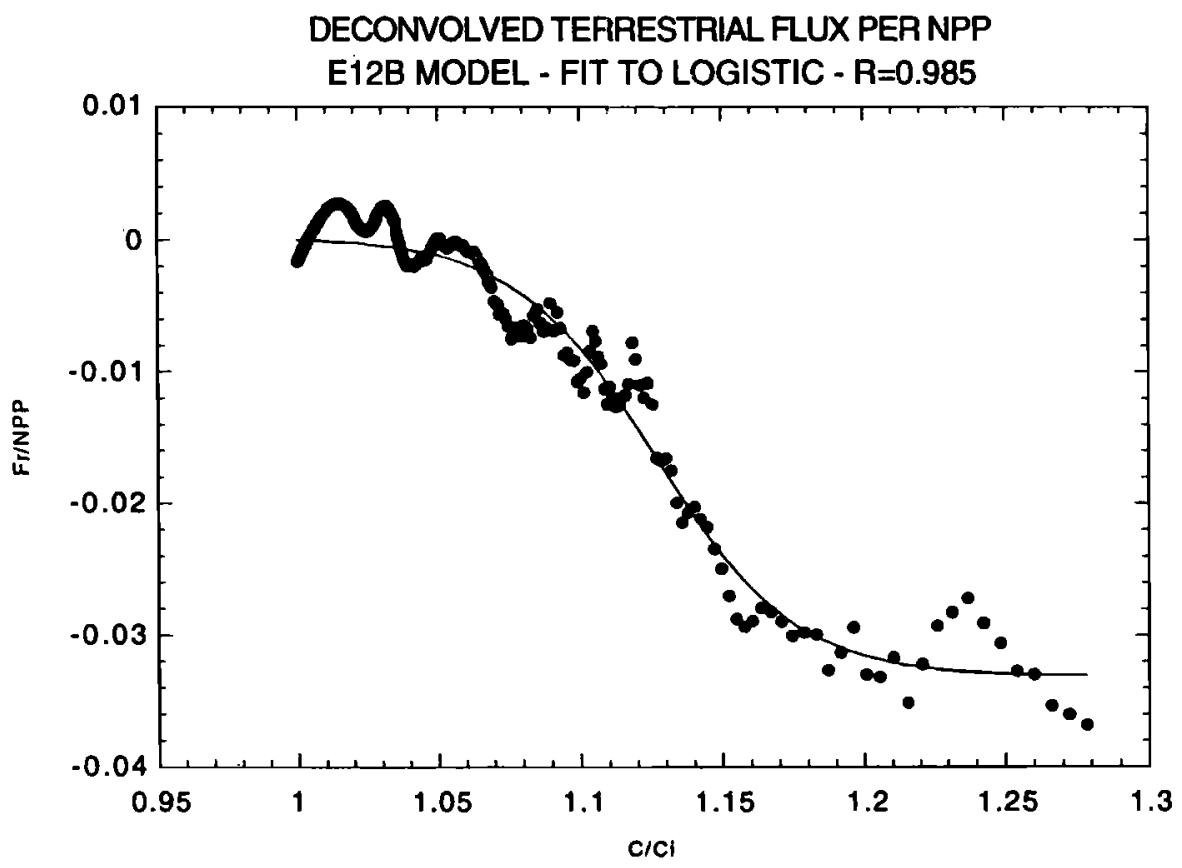

Figure 11. A fit of the function $\rho_{\mathrm{r}}$ to the deconvolved flux divided by the net primary production flux as a function of relative atmospheric $\mathrm{CO}_{2}$ concentration. This graph shows the logistic parameterization (8). 
Table 2. Single Half-Life Results for the OceanAtmosphere Models

\begin{tabular}{cc}
\hline Model & $\mathrm{T}_{1 / 2}, \mathrm{yr}$ \\
\hline 12B & 81 \\
BD1 & 116 \\
OC1 & 42 \\
BD2 & 79 \\
OC2 & 37 \\
\hline
\end{tabular}

$\mathrm{BD} 1$, box-diffusion (preindustrial ${ }^{14} \mathrm{C}$ calibration); $\mathrm{OC} 1$, outcrop diffusion (preindustrial); BD2, box diffusion (bomb ${ }^{14} \mathrm{C}$ calibration); OC2, outcrop diffusion (bomb); 12B, twelve-box model.

$597 \mathrm{Pg}$ respectively, simple algebra yields an equilibrium partial pressure at $326 \mathrm{ppm}$. This number, which we use simply as a reference point, is the theoretical asymptote for the atmospheric $\mathrm{CO}_{2}$ decay curves $c_{i}(t)$. If we terminate the forcing at a present value (e.g., $t_{0}=354 \mathrm{ppm}$ ), $\mathrm{T}_{1 / 2}$ is defined to be the first year after cutoff at which $c(t) \leq 326 \mathrm{ppm}$. We note that small differences could be obtained by varying the Revelle value, by using the more complete mathematical description of the carbonate-borate chemical system [e.g., Bolin et al., 1979; Bolin, 1981), or by assuming different concentrations of dissolved inorganic carbon.

\section{Results Using Single Half-Life}

In this section we explore the response of the global carbon cycle models (E-BD, E-OC, and E-12B) when the inputs $\left(\mathrm{F}_{\mathrm{FE}}\right.$ and $F_{B}$ ) are reduced instantaneously to zero under two separate conditions: when we allow $F_{r}$ to operate for all $t$ and when there is no $\mathrm{F}_{\mathrm{r}}$. We compare these results to a similar calculation of single half-lives involving only the three ocean-atmosphere systems (BD, OC, 12B). Finally, to connect to the results reported by Intergovernmental Panel on Climate Change [Watson et al., 1990], we compute in a subsequent section the classical lifetimes of $\mathrm{CO}_{2}$ using the three ocean-atmosphere models as well as when the terrestrial sink is included.
Tables 2 and 3 show the $T_{1 / 2}$ values calculated using the atmosphere-ocean models (12B, BD, and $\mathrm{OC}$ ) standing alone (Table 2), using the coupled terrestrial models (E-12B, E-BD, and E$O C$; the latter two, again, with two parameterizations for the ocean submodels) with regrowth alone assumed (Table 3, row 1) and assuming both regrowth and fertilization, which is described with the three different schemes discussed in section 3 (Table 3 , rows 2-4). We can see that without the fertilization flux these models yield single half-lives from as high as 116 years (BD, preindustrial ${ }^{14} \mathrm{C}$ calibration) to as low as 37 years $\left(\mathrm{OC}\right.$, bomb ${ }^{14} \mathrm{C}$ calibration). The ranges would narrow considerably if the Outcrop-Diffusion (OC) model were dropped. It also narrows when the biosphere is included with regrowth alone assumed. This simply adds a uniform sink to each system, which aids the ocean-atmosphere systems that have an ocean surface bottleneck problem in the removal of carbon (i.e. the $O C$ and 12B systems). The single half-lives are obviously reduced; they are even more significantly reduced if one includes a fertilization sink (Table 3 , rows 2-4). In part, this is simply the addition of a sink, as was the case in including forest regrowth; however, there is a further compensating factor that the sink strength is not uniform. Namely, the model oceans which are more efficient at taking up excess $\mathrm{CO}_{2}$ require a smaller $\mathrm{F}_{\mathrm{r}}$ flux to match the $\mathrm{pCO}_{2}$ record, and vice versa. This is also reflected in the regression coefficients for the OC models (see Table 4); $F_{r}$ is close enough to zero that random fluctuations in the residual nearly overwhelm the assumed logarithmic trend.

Plots of the relaxation curves associated with the ocean-atmosphere results (Table 2), for all ocean models, are shown as Figure 12. This should be compared to the somewhat steeper initial drop when the terrestrial biosphere is included with regrowth alone and the even steeper slopes when fertilization is assumed (Figure 13); in order to compare Figures 12 and 13 we include in Figure 13 the relaxation dynamics of the box-diffusion model with the ${ }^{14} \mathrm{C}$ bomb data used for parameterization. Note that the functional differences for different schemes to incorporate fertilization are unimportant; this is partly a result of the deconvolution methodology which forces the dynamics to fit the same pattern, namely the ice core record, which reduces the effect of differences in the functional forms.

Table 3. Single Half-Life Results for the Ocean-Atmosphere-Terrestrial Models Under Various $\mathrm{CO}_{2}$ Fertilization Assumptions

\begin{tabular}{lccccc}
\hline Parameterization & E-12B & E-BD1 & E-OC1 & E-BD2 & E-OC2 \\
\hline None (regrowth only) & 68 & 86 & 37 & 63 & 33 \\
Logarithmic & 22 & 49 & 28 & 40 & 26 \\
Linear & 19 & 30 & 20 & 33 & 20 \\
Logistic & 20 & 38 & 23 & 33 & 20 \\
\hline
\end{tabular}

Measurements are in years. Notation for the ocean models is the same as in Table 2.

a No fertilization flux in this experiment.

Table 4. Coefficient of Correlation $R$ for the Fit of $F_{r}$ to the Calculated Residual Carbon Flux

\begin{tabular}{lcccrr}
\hline Parameterization & E-12B & E-BD1 & E-OC1 & E-BD2 & E-OC2 \\
\hline Logarithmic & .896 & .914 & .804 & .869 & .746 \\
Linear & .953 & .956 & .895 & .931 & .717 \\
Logistic & .986 & .986 & .958 & .975 & .400 \\
\hline
\end{tabular}




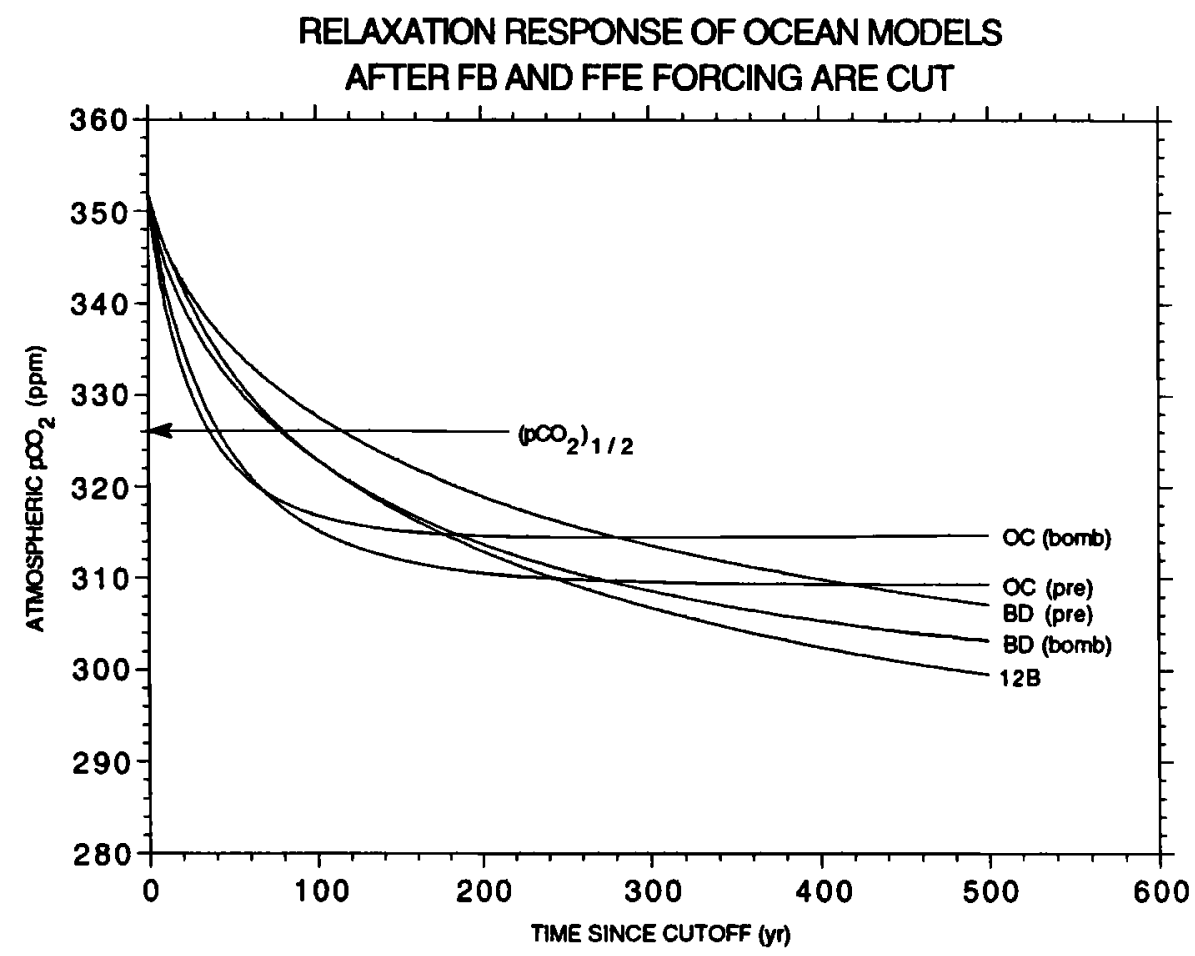

Figure 12. Response of the ocean-atmosphere models to a cessation of all emissions at $t_{0}=1990$. The horizontal arrow represents the $\mathrm{pCO}_{2}$ level halfway between the 1990 value and the theoretical equilibrium value.

In summary, there are small differences in single half-life results associated with the model ocean used and with the nature of the parameterization of the missing flux $F_{r}$ but the principal variation is predominantly due to the inclusion of a terrestrial carbon sink, beyond forest regrowth. Thus the results may be grouped into the following three categories (with associated average values): (1) regrowth and fertilization $\left(\overline{T_{1 / 2}}=27\right.$ years), (2) regrowth and no fertilization $\left(\overline{T_{1 / 2}}=57\right.$ years), and (3) no bio-

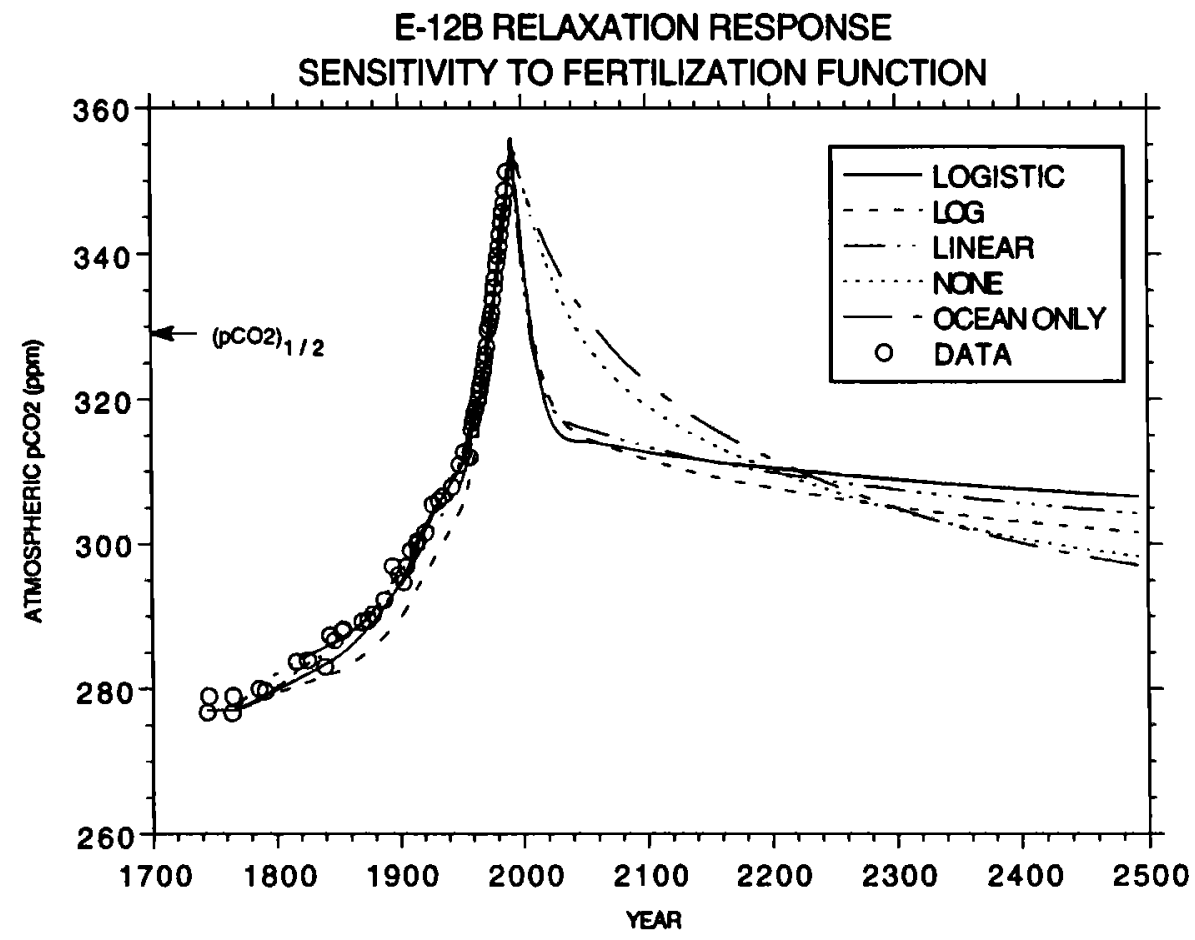

Figure 13. Response of the E-12B (Emanuel terrestrial submodel plus twelve-box ocean) model to the emissions cutoff scenario. Curves are shown which represent the inclusion of three possible parameterizations of fertilization flux, as well as the curve for no fertilization. For comparison we also include the curve for the ocean-onty (12B) case. 
sphere $\left(\overline{T_{1 / 2}}=71\right.$ years). If we drop the OC model, which (as mentioned in section 2.1) mixes atmospheric $\mathrm{CO}_{2}$ instantaneously to deepwaters and perhaps overestimates the rate of ocean uptake, and calculate averages across the 12B model and two versions of the BD model, the single half-lives increase somewhat as follows: (1) regrowth and fertilization, $\left(\overline{T_{1 / 2}}=31\right.$ years), (2) regrowth and no fertilization, $\left(\overline{T_{1 / 2}}=72\right.$ years $)$, and (3) no biosphere, $\left(\overline{T_{1 / 2}}=92\right.$ years $)$. The question of short-term atmospheric $\mathrm{CO}_{2}$ retention is effectively bracketed by these values.

\section{Exponential Characterizations Of Lifetime}

We now turn to a discussion of the traditional notion of atmospheric lifetime and point out some of the difficulties that are inherent in this method when applied to a response which is not an exponential decay. For this discussion we use the definition of Lashof and Ahuja [1990]. The underlying idea in the LashofAhuja definition of atmospheric lifetime is the classical concept of exponential decay

$$
c(t)=\exp (-t / \tau)
$$

where $\tau$ is the decay constant (e-folding) time for the material. There is an immediate consequence of using this simple expression. Namely, the concentration $c(t)$ goes rapidly to zero as $t$ goes to infinity and the integral in (2) is $\tau$. To use this basic concept of exponential decay, Lashof and Ahuja (see also Maier-Reimer and Hasselmann [1987] must accommodate two facts about (most) models of atmospheric $\mathrm{CO}_{2}$. Given a unit pulse of carbon dioxide, the decay is neither exponential nor does it go to zero. Their accommodation is reasonable: fit the response to a weighted sum of exponential decay functions and fix a finite time window for the fit, which in effect ignores the atmospheric concentration after a given length of time.
The mathematical construct requires the following: the calculated concentration $\mathrm{c}(\mathrm{t})$ of atmospheric $\mathrm{CO}_{2}$ following a pulse at time zero in a given atmosphere-ocean model; a temporal interval (the period of consideration, $\left[0, N_{w}\right]$ ); an upper bound $\tau_{\max }$ on the time constant; and the number of terms, say $N$, to be used in the approximation process (the number is not important, only the issue of goodness of fit really matters). One then finds, by constrained least squares fit, non-negative numbers (weights) $a_{1}, \ldots, a_{N}$, where $a_{1}+\ldots+a_{N}=1$, and numbers (e-folding times) $\tau_{1}, \ldots, \tau_{N}$ such that

$$
\mathrm{c}(t) \approx \Sigma_{i} \text { ai } \exp \left(-t / \tau_{i}\right) ; \quad\left(0 \leq t \leq N_{w} \text { and } 0 \leq \tau_{i} \leq \tau_{\max }\right)
$$

By integration of (14) the atmospheric lifetime $T_{\text {res }}$ is then simply the weighted average of the $\tau$ 's (an average e-folding time), i.e.,

$$
T_{\mathrm{res}}=\Sigma_{i} a_{i} \tau_{i}
$$

Lashof and Ahuja used Maier-Reimer and Hasselman's [1987] results and presented a $\mathrm{CO}_{2}$ residence time value of 230 years.

Using the three atmosphere-ocean submodels, we inject an amount of $\mathrm{CO}_{2}$ into the atmosphere component of the models equal to $25 \%$ of the amount presently in our atmosphere. Each system then relaxes to different steady state values (Figure 14): approximately $10-20 \%$ of the pulse remaining, depending on the specification of equilibrium carbonate chemistry in the model. This relaxation curve is approximated by a weighted sum of exponentials (i.e., (14)) under assumptions of $N_{w}, N$, and $\tau_{\max }$. The results are summarized in Table 5. Some of the results are, at first glance, counterintuitive; the most efficient ocean model (OC) can yield a longer calculated atmospheric lifetime than the less efficient ocean models. This is an artifact of the relative quickness that the OC model reaches an asymptotic value. Simply stated, the greater the overlap of the fitting window $\left(0 \leq t \leq N_{w}\right)$ with a

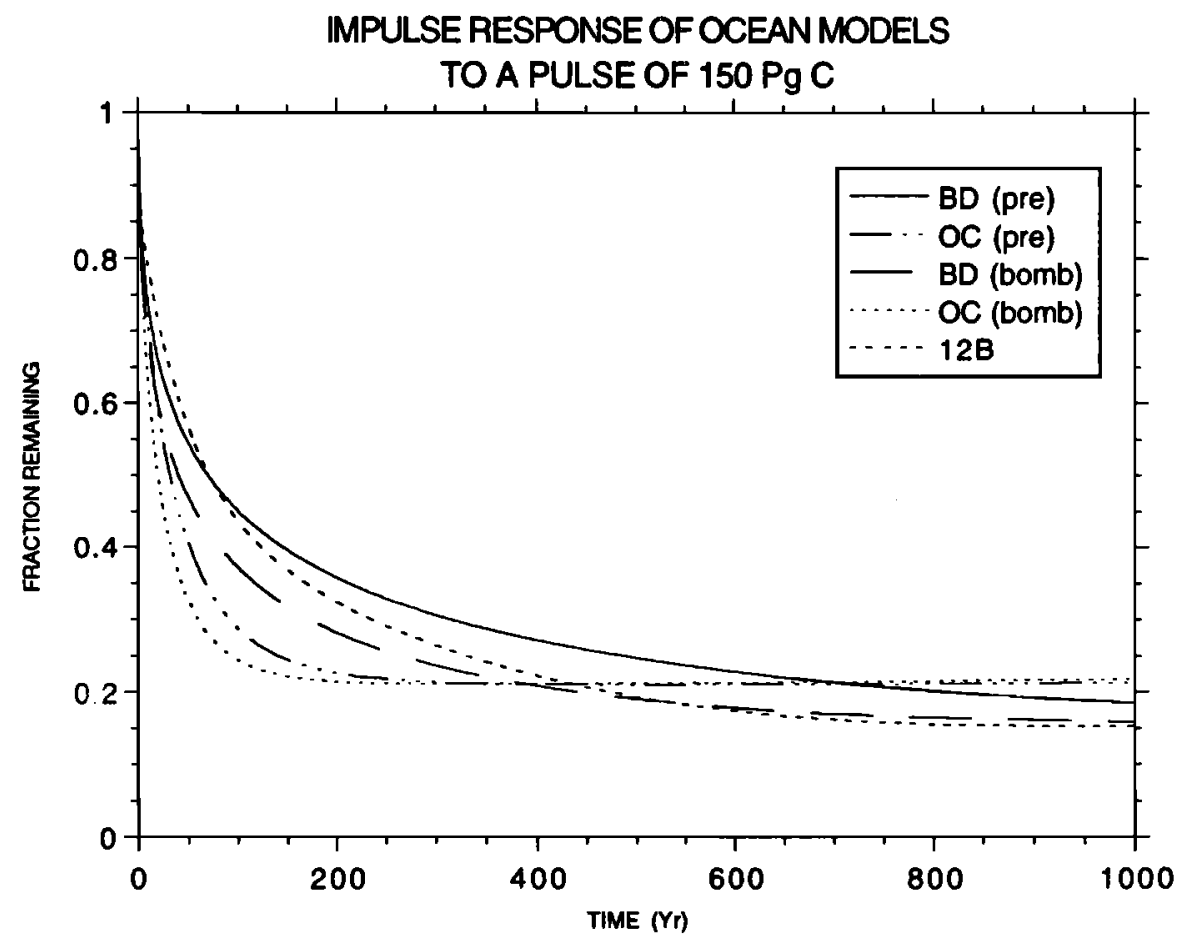

Figure 14. Response of the ocean-atmosphere models to an instantaneous pulse of $\mathrm{CO}_{2}$ equivalent to $25 \%$ of the present value. The origin of the time axis is $t=0$ because no historical emissions are used. 
Table 5. Sensitivity of $T_{\text {res }}$ for the Ocean-Atmosphere Models

\begin{tabular}{|c|c|c|c|c|}
\hline \multicolumn{2}{|c|}{ Numerical Parameters, yr } & \multicolumn{3}{|c|}{$T_{\text {res }}$ for Each Ocean Model, yr } \\
\hline$N_{w}$ & $\tau_{\max }$ & BD & OC & $12 \mathrm{~B}$ \\
\hline 50 & 500 & 132.7 & 114.3 & 236.8 \\
\hline 50 & 1000 & 262.1 & 202.9 & 231.6 \\
\hline 50 & 5000 & 1133.0 & 930.1 & 612.0 \\
\hline 100 & 500 & 170.9 & 123.0 & 243.4 \\
\hline 100 & 1000 & 253.8 & 205.4 & - \\
\hline 100 & 5000 & 667.5 & 871.0 & - \\
\hline 200 & 500 & 204.9 & 160.3 & 256.3 \\
\hline 200 & 1000 & 287.4 & 271.2 & 262.8 \\
\hline 200 & 5000 & 250.6 & 567.2 & 262.8 \\
\hline 500 & 500 & 230.1 & - & 259.9 \\
\hline 500 & 1000 & 320.7 & - & 348.8 \\
\hline 500 & 5000 & 490.5 & 1147.0 & 283.9 \\
\hline 1000 & 500 & - & - & - \\
\hline 1000 & 1000 & - & - & - \\
\hline 1000 & 5000 & 1015.0 & - & 963.7 \\
\hline
\end{tabular}

Missing values indicate poor fit $\left(X^{2} \geq 0.1\right)$.

period where the change (or the derivative) in the simulated atmospheric concentration is near zero, the greater the necessity that the fitting term must contain exponentials that are as flat as possible (i.e., very large $\tau$ 's).

For the purposes of comparison we used $N_{w}$ values of 50, 100, 200,500 , and 1000 years (Table 5). In general, increasing the interval (for a given model, and leaving $\tau_{\max }$ fixed) leads to an increase in the value of. $T_{\text {res }}$ or a failure of the fitting routine since the larger interval includes more of the curve that is relatively flat. This sensitivity is why the choice of a reasonable value for $N_{w}$ is important. Unfortunately there is no clear guideline. Moreover, this sensitivity to $N_{w}$ is also connected with the sensitivity of $T_{\text {res }}$ to the assumed $\tau_{\max }$.

To the extent that $\mathrm{c}(\mathrm{t})$ approaches 0 for $\mathrm{t} \rightarrow N_{w}$, then the least squares routine will attempt to return very high $\tau_{i}$ values (because the function is not decaying rapidly). Consequently, one needs to place a size constraint on the $\tau$ 's (i.e., $\tau_{\max }$ ). Unfortunately, for a given window $\left(N_{w}\right)$ the calculated residence time is strongly dependent on this constraint (Table 5). This is partly a numerical artifact of the over-determined inversion process, in which minimizing error can lead to instabilities (for example, see the $X^{2}$ values in Table 6). Figure 15 shows a plot of $c(t)$ for two different values of $\tau_{\max }$. The fitted curves are very different beyond the window $N_{w}$.

It appears that the numerical sensitivity of $T_{\text {res }}$ may not have been sufficiently well appreciated; however, Lashof and Ahuja
[1990] do note this sensitivity to one aspect of the calculation when they discuss changing the constraint to $\tau_{i} \leq 1000$. In their study this $\tau_{\max }$ sensitivity was dealt with in a different way. They did not fit a $c(t)$ term but rather used parameter values (based on Green's function) from a Maier-Reimer and Hasselman study

$$
\begin{aligned}
& \tau_{i}=(1000,362.9,73.6,17.3,1.9) \\
& a_{i}=(0.131,0.201,0.321,0.249,0.098)
\end{aligned}
$$

In other words, they took as given a weighted exponential form for $c(t)$. It was noted that the large $\tau_{0}=1000$ value effectively discounts long-term $\mathrm{CO}_{2}$ retention. (This value was a fitting constraint used by Maier-Reimer and Hasselmann.) Specifically, changing $\tau_{0}$ from 1000 to 3000 and refitting the $a_{i}$ values led to a more than doubling of residence time from 230 to 500 years. This is consistent with our results.

In an attempt to connect these results with the earlier single half-life calculations we perform the same experiment with the scenario-based relaxation of the BD and the E-BD models, with terrestrial biosphere and no fertilization and with a $\mathrm{CO}_{2}$-fertilized terrestrial biosphere (Table 7). We find the same problems associated with the calculation of $T_{\text {rea. }}$ Often the combinations that clearly reduce $\mathrm{CO}_{2}$ concentration the fastest, such as including fertilization, have longer lifetimes. There was a similar counterintuitive result mentioned when discussing the results of the atmosphere-ocean systems (Table 5); the most efficient ocean model

Table 6. Goodness of Fit for Selected Runs From Table 5

\begin{tabular}{ccccc}
\hline \multicolumn{2}{c}{ Numerical Parameters, $y \mathbf{r}$} & \multicolumn{3}{c}{$X^{2}$ of Fit for Each Ocean Model } \\
\cline { 4 - 5 }$N_{w}$ & $\tau_{\max }$ & BD & OC & $12 \mathrm{~B}$ \\
\cline { 5 - 5 } 50 & 500 & $1.9 \mathrm{e}-7$ & $1.2 \mathrm{e}-5$ & $7.1 \mathrm{e}-8$ \\
50 & 1000 & $1.2 \mathrm{e}-5$ & $1.1 \mathrm{e}-5$ & $3.8 \mathrm{e}-8$ \\
50 & 5000 & $1.1 \mathrm{e}-5$ & $9.7 \mathrm{e}-6$ & $3.8 \mathrm{e}-8$ \\
1000 & 500 & 3.92 & 12.9 & 0.34 \\
1000 & 1000 & 0.21 & 0.27 & 0.10 \\
1000 & 5000 & $1.1 \mathrm{e}-3$ & 0.20 & $1.4 \mathrm{e}-2$ \\
\hline
\end{tabular}




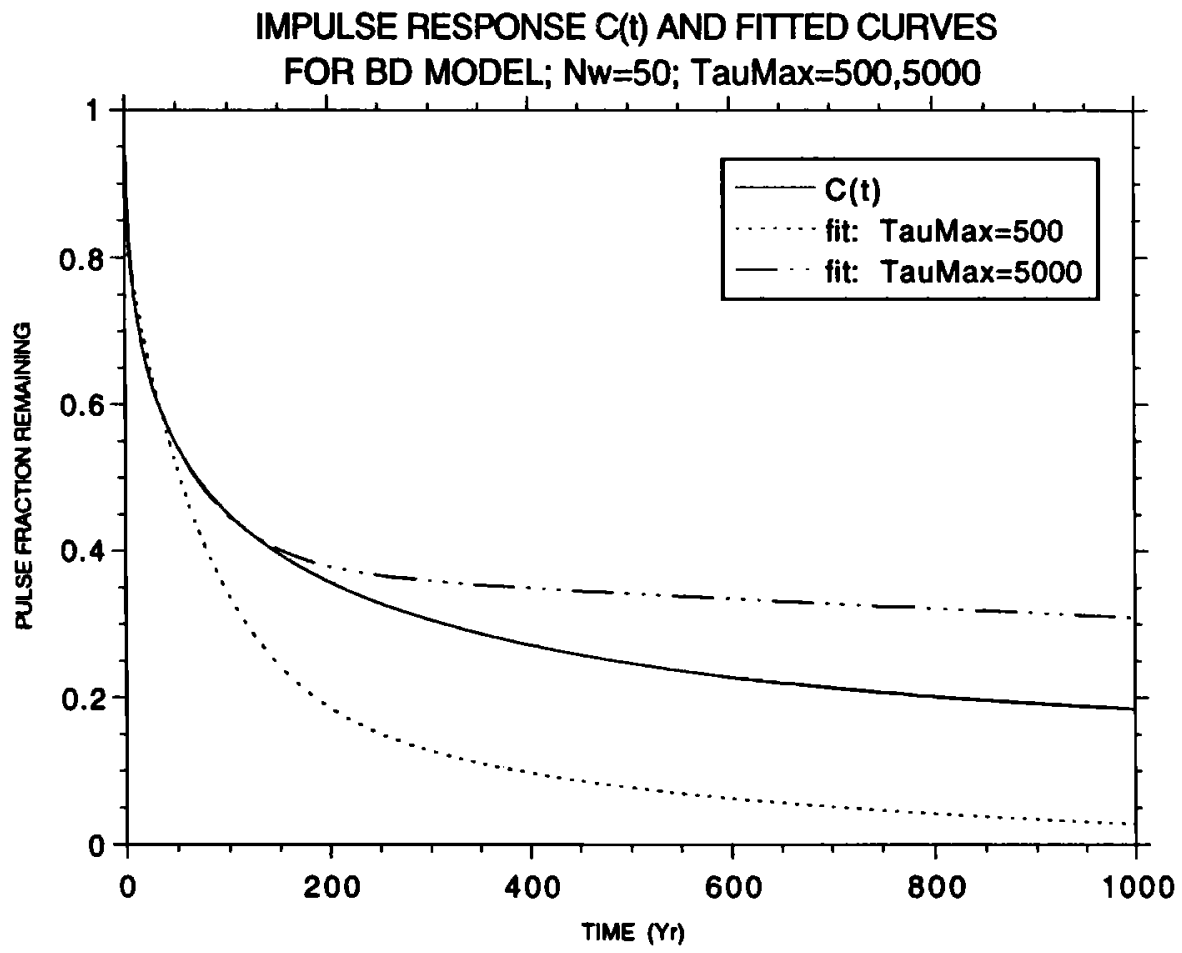

Figure 15. Response of the box-diffusion model to an instantaneous pulse and two curves fitted by the least squares method to the response $c(t)$. For these curves, $N_{w}=50, N=4$, and there are two different values of $\tau_{\max }(500$ and 5000).

(OC) often yielded a longer calculated atmospheric lifetime than the less efficient ocean models.

There are a number of difficulties with the exponential-based method that should be addressed. On the basis of these results, we may conclude that most of the $T_{\text {res }}$ values are, in some sense, determined by the constraints placed on the parameters $\tau_{i}$, and by the assumption about $N_{w}$. In other words, $T_{\text {res }}$ could be considered arbitrary unless there is some otherwise logical means for choosing (based on physical considerations) reasonable fitting constraints.

Table 7. Sensitivity of $T_{\text {res }}$ for the E-BD OceanAtmosphere-Terrestrial Model

\begin{tabular}{ccccc}
\hline \multirow{2}{*}{ Numerical Parameters, yr } & & \multicolumn{2}{c}{$T_{\text {res, yr }}$} \\
\cline { 1 - 2 } \cline { 5 - 5 }$N_{w}$ & $\tau_{\max }$ & & $\begin{array}{c}\text { Biosphere } \\
\text { Included }\end{array}$ & $\begin{array}{c}\text { Fertilized } \\
\text { Biosphere }\end{array}$ \\
\hline 50 & 500 & & 351.8 & 258.2 \\
50 & 1000 & & 561.6 & 465.5 \\
50 & 5000 & & 1591.6 & 2128.7 \\
100 & 500 & & 375.4 & 273.7 \\
100 & 1000 & & 391.9 & 512.6 \\
100 & 5000 & & 401.1 & 2334.8 \\
200 & 500 & & 379.9 & - \\
200 & 1000 & & 560.3 & 528.2 \\
200 & 5000 & & 1354.1 & 1186.7 \\
500 & 500 & & - \\
500 & 1000 & 619.1 & - \\
500 & 5000 & 840.6 & 2135.3 \\
\hline
\end{tabular}

Missing values indicate poor fit $\left(X^{2} \geq 0.1\right)$.

\section{Conclusions}

It is necessary for policy applications to have a consistent method for estimating the relative contributions of the anthropogenic, radiatively active trace gases to potential climate change. The GWP is one method, but we have shown in section 6 that the estimation of the integral in the denominator of the GWP formula (1) is ambiguous. As an interim step, we have introduced a simple indicator of the Earth system's ability to remove excess atmospheric $\mathrm{CO}_{2}$, the single half-life $\left(\mathrm{T}_{1 / 2}\right)$. This indicator is free from the numerous difficulties and numerical instabilities associated with a conventional lifetime calculation. Thus one could envision a modified GWP, in which the single half-lives of the radiatively important gases replace the integral in (1).

We have found that the inclusion of an active (donor and recipient controlled) terrestrial biosphere considerably alters modeled estimates of the effective lifetime of atmospheric $\mathrm{CO}_{2}$. Moreover, since this factor is the dominant source of variation, we group the results into three categories: biosphere with fertilization flux ( $\overline{T_{1 / 2}}=27$ years), biosphere without fertilization flux $\left(\overline{T_{1 / 2}}=57\right.$ years), and no biosphere (purely an ocean atmosphere system; Table 2 ), then $\overline{T_{1 / 2}}=71$ years. If we drop the outcropdiffusion model, which is extremely efficient in taking up $\mathrm{CO}_{2}$ from the atmosphere, then these results change in detail but not in pattern: biosphere with fertilization flux $\left(\overline{T_{1 / 2}}=31\right.$ years $)$, biosphere without fertilization flux ( $\overline{T_{1 / 2}}=72$ years), and no biosphere (purely an ocean atmosphere system; Table 2), then $\overline{T_{1 / 2}}=92$ years.

The inclusion of an active (donor and recipient controlled) terrestrial biosphere clearly and considerably alters our estimates of the effective lifetime of atmospheric $\mathrm{CO}_{2}$. Several important and difficult scientific questions remain. Does this terrestrial sink exist? Will it continue to operate or has it begun to saturate? What is the effect of changes in other biogeochemical cycles? What if 
climate begins to shift; does that increase or decrease the terrestrial sink? How will the oceans respond? These are also important policy questions.

Acknowledgments. This work was supported, in part, by grants from the National Aeronautical and Space Administration, the Environmental Protection Agency, and the Science and Engineering Education Division of the Department of Energy.

\section{References}

Aber, J. D., and J. M. Melillo, Terrestrial Ecosystems., 427 pp., Saunders College Publishing, Philadelphia, 1991.

Andres, R. J., G. Marland, T. Boden, and S. Bischoff, Carbon dioxide emissions from fossil fuel combustion and cement manufacture 17511991 and an estimate of their isotopic composition and latitudinal distribution, in Proceedings from the 1993 Global Change Institute: The Carbon Cycle, UCAR Office for interdisciplinary Earth Studies, Boulder, Colo., in press, 1993.

Bacastow, R., and C. D. Keeling, Atmospheric carbon dioxide and radiocarbon in the natural carbon cycle: II, Changes from A.D. 1700 to 2070 as deduced from a geochemical model, in Carbon and the Biosphere, NTIS document, CONF-720510, pp. 86-135, U.S. At. Energy Comm., Springfield, Va, 1973.

Bazzaz, F. A., The response of natural ecosystems to the rising global $\mathrm{CO}_{2}$ levels. Ann. Rev. Ecol. Sys. 21, 167-196, 1990.

Bazzaz, F. A., and E. D. Fajer, Plant life in a $\mathrm{CO}_{2}$-rich world, Sci. Am. 266:1, 68-74, 1992.

Bolin, B. (Ed.), Carbon Cycle Modeling, SCOPE 16, 340 pp., John Wiley, New York, 1981.

Bolin, B., and I. Fung, The carbon cycle revisited, in Proceedings from the 1990 Global Change Institute: Modeling the Earth System, pp. 151-164, UCAR Office for Interdisciplinary Earth Studies, Boulder, Co., 1992.

Bolin, B., E. T. Degens, S. Kempe, and P. Ketner, (Eds.), The Global Carbon Cycle, SCOPE 13, John Wiley, New York, 1979.

Bolin, B. A., A. Björkstrom, K. Holmén, and B. Moore III, The simultaneous use of tracers for ocean circulation studies. Tellus 35B, 206236, 1983.

Björkstrom, A., A model of $\mathrm{CO}_{2}$ interaction between atmosphere, oceans, and land biota, in The Global Carbon Cycle, SCOPE 13, pp. 403-457, John Wiley, New York, 1979.

Broecker, W. S., Keeping global change honest. Global Biogeochem. Cycles, 5(3), 191-192, 1991.

Broecker, W. S., and T.-H. Peng, Tracers in the Sea. Lamont-Doherty Geol. Obs., Columbia University Press, Palisades, N.Y., 1982

Broecker, W. S. and T.-H. Peng, Evaluation of the ${ }^{13} \mathrm{C}$ constraint on the uptake of fossil fuel $\mathrm{CO}_{2}$ by the ocean, Global Biogeochem. Cycles, 7 , 619-626, 1993.

Dai, A., and I. Fung, Can climate variability contribute to the missing $\mathrm{CO}_{2}$ sink7 Global Biogeochem. Cycles, 7, 599-609, 1993.

Diaz, S., J. P. Grime, J. Harris, and E. McPherson, Evidence of a feedback mechanism limiting plant response to elevated carbon djoxide, Nature, 364, 616-617, 1993.

Emanuel, W. R., G. G. Killough, W. M. Post, and H. H. Shugart, Modelling terrestrial ecosystems in the global carbon cycle with shifts in carbon storage capacity by land use change. Ecology , 65, 970-983, 1984.

Friedli, H., H. Lötscher, H. Oeschger, U. Siegenthaler, and B. Stauffer, Ice core record of ${ }^{13} \mathrm{C} /{ }^{12} \mathrm{C}$ ratio of atmospheric $\mathrm{CO}_{2}$ in the past two centuries, Nature, 324, 237-238, 1986.

Garbutt, K., W. E. Williams, and F. A. Bazzaz, Analysis of the differential response of five annuals to elevated $\mathrm{CO}_{2}$ during growth. Ecology , 71:3, 1185-1194, 1990.

Gates, W. L., J. F. B. Mitchell, G. J. Boer, U. Cubasch, and V. P. Melesko, Climate modelling, climate prediction, and model validation, in Climate Change 1992: The Supplementary Repor to the IPCC Scientific Assessment, pp. 103-134, Cambridge University Press, New York, 1992.
Houghton, R. A., Tropical deforestation and atmospheric carbon dioxide, Clim. Change, 19, 99-118, 1991.

Houghton, R. A., Is carbon accumulating in the Northern temperate zone? Global Biogeochem.Cycles, 7, 611-617, 1993a.

Houghton, R. A.,Emissions of carbon from land-use change, Proceedings from The 1993 Global Change Institute: The Carbon Cycle, UCAR Office for Interdisciplinary Earth Studies, Boulder, Colo., in press, 1993b.

Houghton, R. A., J. E. Hobbie, J. M. Melillo, B. Moore, B. J. Peterson, G. R. Shaver, and G. M. Woodwell, Changes in the carbon content of terrestrial biota and soils between 1860 and 1980: A net release of $\mathrm{CO}_{2}$ to the atmosphere. Ecol. Monogr. ,53, 235-262, 1983.

Houghton, R. A., and D. L. Skole, Changes in the global carbon cycle between 1700 and 1985, inThe Earth Transformed by Human Action., pp. 393-408, Cambridge University Press, New York, 1991.

Houghton, R. A., D. L. Skole, and D. S. Lefkowitz, Changes in the Landscape of Latin America between 1850 and 1980: II. A net release of $\mathrm{CO}_{2}$ to the atmosphere, For. Ecol. Manage., 38, 173-199, 1991.

Isaksen, I. S. A., J. Ramaswamy, H. Rodhe, and T. M. L. Wigley, Radiative forcing of climate, in Climate Change 1992: The Supplementary Report to the IPCC Scientific Assessment, pp. 53-66, Cambridge University Press, New York, 1992.

Keeling, C. D., Atmospheric $\mathrm{CO}_{2}$ concentrations - Mauna Loa Observatory, Hawaii 1958-1986, NDP-001/R1, Carbon Dioxide Inf. Anal. Cent., Oak Ridge Natl. Lab., Oak Ridge, Tenn., 1986.

Keeling, C. D., S. C. Piper, and M. Heimann, A three-dimensional model of atmospheric $\mathrm{CO}_{2}$ transport based on observed winds: 4 , Mean annual gradients and interannual variability, in Aspects of Climate Variability in the Pacific and Western Americas, Geophy. Monog. Ser., vol. 55, edited by D. H. Peterson, pp. 305-363, AGU, Washington, D.C., 1989.

Lashof, D. A., and D. R. Ahuja, Relative contributions of greenhouse gas emissions to global warming. Nature, 344, 529-531, 1990.

Maier-Reimer, E., Geochemical cycles in an OGCM part 1, Preindustrial tracer distributions, Global Biogeochem. Cycles, 7, 645-677, 1993.

Maier-Reimer, E., and K. Hasselmann, Transport and storage of $\mathrm{CO}_{2}$ in the ocean - An inorganic ocean-circulation carbon cycle model, Climate Dyn., 2, 63-90, 1987.

Marland, G., Fossil fuel $\mathrm{CO}_{2}$ emissions: Three countries account for $50 \%$ in 1988. CDIAC Communications, pp. 1-4, Carbon Dioxide Inf. Anal. Cent., Oak Ridge Natl. Lab., Oak Ridge, Tenn., 1989.

Mitchell, J. F. B., S. Manabe, V. Meleshko, and T. Tokioka, Equilibrium Climate Change - And its Implications for the Future, in Climate Change: The IPCC Scientific Assessment., pp. 131-172, Cambridge University Press, New York, 1990.

Moore, B., The oceanic sink for excess atmospheric carbon dioxide, inWastes in the Ocean: Energy Wastes in the Ocean, vol. 4, pp. 95-125 John Wiley, New York, 1985.

Moore, B., Four simple ocean carbon models, in Proceedings from the 1990 Global Change Institute: Modeling the Earth System, pp. 197223, UCAR Office for Interdisciplinary Earth Studies, Boulder, Colo., 1992.

Neftel, A., E. Moor, H. Oeschger, and B. Stauffer, Evidence from polar ice cores for the increase in atmospheric $\mathrm{CO}_{2}$ in the past two centuries, Nature, 315, 45-47, 1985.

Oeschger, H., U. Siegenthaler, U. Schotterer, and A. Gugelmann, A boxdiffusion model to study the carbon dioxide exchange in nature, Tellus, 27, 168-192, 1975.

Raynaud, D., and J-M. Barnola, An Antarctic ice core reveals $\mathrm{CO}_{2}$ : The major uncertainties. Global Biogeochem. Cycles, 5:4, 309-314, 1985.

Rotty, R. M., and G. Marland, Production of $\mathrm{CO}_{2}$ from fossil fuel burning by fuel type, 1860-1982, Rep. NDP-006, Carbon Dioxide Inf. Anal. Cent., Oak Ridge Nat. Lab., Oak Ridge, Tenn., 1981.

Sarmiento, J. Oceanic uptake of $\mathrm{CO}_{2}$ : The major uncertainties. Global Biogeochem. Cycles, 5:4, 309-314, 1991.

Sarmiento, J., Atmospheric $\mathrm{CO}_{2}$ stalled, Nature, 365, 697-698, 1993.

Schlesinger, W. H., Biogeochemistry: An Analysis of Global Change, 443 pp., Academic, San Diego, Calif., 1991.

Shine, K. P., R. G. Derwent, D. J. Wuebbles, and J-J. Morcrette, 
Greenhouse gases and aerosols, in Climate Change: The IPCC Scientific Assessment, pp. 42-68, Cambridge University Press, New York, 1990.

Siegenthaler, U., Uptake of excess $\mathrm{CO}_{2}$ by an outcrop-diffusion model of the ocean, J. Geophys. Res., 88, 3599-3608, 1983.

Siegenthaler, U., Glacial-interglacial atmospheric $\mathrm{CO}_{2}$ variations. in Proceedings from the 1989 Global Change Institute: Global Changes of the Past, pp. 245-260, UCAR Office for Interdisciplinary Studies, Boulder, Colo., 1989.

Siegenthaler, U. and $\mathrm{H}$. Oeschger, Biospheric $\mathrm{CO}_{2}$ emissions during the past 200 years reconstructed by deconvolution of ice core data, Tellus , 39B, 140-154, 1987.

Skole, D. and C. Tucker, Tropical deforestation and habitat fragmentation in the Amazon: Satellite data from 1978 to 1988, Science, 260, 1905 1910, 1993.

Strain, B. R. and J. D. Cure (1985) Direct effects of increasing carbon dioxide on vegetation. National Technical Information Service, Springfield, Va., 1985.
Tans, P. P., I. Y. Fung, and T. Takahashi, Observational constraints on the global atmospheric $\mathrm{CO}_{2}$ budget, Science, 247, 1431-1438, 1990.

Watson, R. T., H. Rodhe, H. Oeschger, and U. Siegenthaler, Greenhouse gases and aerosols, in Climate Change: The IPCC Scientific Assessment, pp. 1-40, Cambridge University Press, New York, 1990.

Watson, R. T., L. G. Meira Filho, E. Sanhueza, A. Janetos, Greenhouse gases and aerosols, in Climate Change 1992: The Supplementary Report to the IPCC Scientific Assessment, pp. 25-46, Cambridge University Press, New York, 1992.

B. Moore, III and B. H. Braswell, Institute for the Study of Earth, Oceans, and Space, University of New Hampshire, Durham, NH 03824. (e-mail: braswell@ncar.ucar.edu)

(Received February 17, 1993; revised November 29, 1993;

accepted December 1, 1993.) 